\title{
ESTATURA, NUTRICION Y NIVEL DE VIDA EN MURCIA, 1860-1930 *
}

\author{
JOSE MIGUEL MARTINEZ CARRION \\ Universidad de Murcia
}

En este artículo muestro las relaciones que se establecen entre los cambios económicos y el estado del nivel de vida en las diferentes condiciones sociales de una población, $y$, más concretamente, los efectos existentes entre los cambios agrarios y las pautas de nutrición y morbilidad con las tendencias de la estatura mostradas a lo largo de varias generaciones en la comarca de Murcia, durante la segunda mitad del siglo xIx y las primeras décadas del siglo xx. Los resultados que se exponen a lo largo de estas páginas constituyen una primera aproximación a un trabajo más elaborado que realizo sobre las interrelaciones y los vínculos que se establecen entre indicadores antropométricos (estatura, peso) e indicadores socioeconómicos (renta, nutrición, sanidad), como consecuencia de una determinada conducta social, demográfica y económica. Resultados, por otra parte, que tienen que ver con la coyuntura económica por la que atraviesa Murcia en este período y la peculiaridad de sus componentes sociales y demográficos.

La utilización de la talla de los individuos como indicador socioeconómico no es reciente ${ }^{1}$; sin embargo, su uso se ha venido generalizando entre los historiadores económicos en estos últimos años ${ }^{2}$ para explicar los efectos de

* El presente trabajo es una versión de la comunicación presentada al III Congreso de Historia Económica, celebrado en Segovia durante los días 3 al 5 de octubre de 1985. Quiero agradecer los comentarios y críticas sugeridos al mismo por Francisco Bustelo y, especialmente, por Josep Fontana, que han enriquecido la versión definitiva del texto. Asimismo, agradezco el apoyo y estímulo de Vicente Pérez Moreda en la realización final del texto. Miguel Rodríguez Llopis y Angela Hernández Moreno ayudaron en la búsqueda y recogida de datos. Pero, en cualquier caso, su elaboración e interpretación es responsabilidad exclusiva del autor.

1 Aron, Dumont y Le Roy Ladurie (1972).

2 Interesados por la medición de los cambios en los niveles de vida, un nutrido grupo de historiadores económicos, auspiciados por el Departamento Nacional de Investigaciones Económicas (NBER) de los Estados Unidos, y bajo la tutela de los profesores Fogel, Engerman y Floud, ha venido publicando diversos trabajos relacionados con los cambios de la estatura en diversas regiones de Europa y Estados Unidos, con resultados desiguales. Véanse, en este sentido, Fogel y Engerman (1982), edición de un número monográfico de la revista Social Science History; Wachter (1981), Steckel (1982), Floud (1983, 1984), Margo y Steckel (1983), y el artículo conjunto realizado por Fogel, Engerman, Floud, 
las mejoras en los niveles nutritivos y la composición de la dieta alimenticia sobre el comportamiento socioeconómico, especialmente sobre la productividad del trabajo en las distintas esferas de la producción, la selección de individuos para determinadas ocupaciones y, entre otros factores, la correspondencia con el declive de la mortalidad. De esta manera, a las ya clásicas medidas y parámetros socioeconómicos, tales como los índices de precios al consumo y salarios reales, estimaciones de renta per capita, evaluaciones del consumo alimenticio y tablas de mortalidad, que reflejan en buena medida el nivel de vida de productores y consumidores y, en definitiva, las condiciones sociales del capital humano ${ }^{3}$, hemos de añadir, ahora, el análisis y medición de la estatura a una edad específica y sus cambios a lo largo de varias generaciones, como uno más de los procedimientos válidos para la estimación de la naturaleza y las transformaciones que acontecen en el nivel de bienestar de la población.

La teoría del crecimiento humano descansa, a juicio de fisiólogos, nutricionistas y antropólogos, en las interrelaciones que se establecen entre factores genéticos y ambientales, operando estos últimos a través de la nutrición, higiene y salud. Existe, por tanto, unanimidad entre los especialistas acerca del papel que ejerce la nutrición y la enfermedad en la estatura media final de las poblaciones ${ }^{4}$. Y se ha demostrado que los cambios de estatura durante el período de crecimiento - el más rápido y decisivo está considerado entre los 13 y 17 años de edad - tienen bastante que ver con los niveles de nutrición y composición de la dieta alimenticia, o, lo que es lo mismo, con la distribución social de la renta y la capacidad de poder adquisitivo de productores y consumidores ${ }^{5}$. Períodos cortos, pero severos, y períodos no tan acusados, pero prolongados, de desnutrición, impiden el desarrollo normal del cuerpo humano y alcanzar la estatura media óptima a la edad adulta, llegando a producir, si la desnutrición es acusada en un espacio de tiempo duradero, verdaderas situaciones de malformación, raquitismo y encanijamiento ${ }^{6}$. En este sentido, la relación recíproca entre enfermedad y estatura es uno de los factores que se muestran a lo largo de estas páginas, junto a las secuelas que de ello se derivan en la productividad del trabajo. Por otro lado, los cambios que se producen en la estatura media final -alcanzada en torno a los 20-25 años de edad - van a reflejar no sólo el estado nutricional que se extiende en sus

Steckel, Trusell, Wachter, Sokoloff, Villaflor, Margo y Friedman (1983). Más recientemente, en varios trabajos de John Komlos (1985). En la Universidad de Gante, en Bélgica, han destacado las investigaciones que lleva a cabo Chris Vanderbroeke $(1981,1982)$. A estos autores debo el conocimiento de algunos de sus trabajos aún no publicados.

${ }^{3}$ Una muestra de ellas véase en los trabajos de Ashton (1949), Hobsbawn (1963), Taylor (1975) y Lindert y Williamson (1983).

- Tanner (1981), Grenne y Johnson (1980).

' Steckel (1982).

- Tanner (1982). 
años de crecimiento, sino también el estado nutricional acumulado por sus padres, sobre todo en la nutrición de las madres y, tal vez, de sus abuelas. Sin menoscabar la decisiva influencia de factores sociogenéticos y etnográficos, puede afirmarse que la desnutrición de una generación puede afectar a la estatura de las generaciones subsiguientes, mostrando una talla media casi idéntica o similar a las siguientes, si las condiciones ambientales y socioeconómicas no han cambiado sustancialmente.

\section{Algunas precisiones sobre las fuentes}

Las series de los censos anuales de reclutas para las fuerzas armadas constituyen la principal fuente de explotación para el análisis de los caracteres antropométricos de la población, y son, junto a las series parroquiales de defunción durante este período, una de las fuentes más ricas para la estimación del nivel de vida de las clases trabajadoras y casi del conjunto de la sociedad, aunque sea tan sólo a través de la naturaleza fisiológica de la población masculina en torno a los 19-21 años ${ }^{7}$. Los datos utilizados en este caso se encuentran en los Cuadernos para la declaración y clasificación de soldados o Expedientes de Reemplazo, acompañados normalmente de unos "Cuadernos de los mozos que se juzgan» para el año correspondiente, donde se incluyen todos los relacionados y mozos definitivamente alistados con sus respectivas tallas. Previa clasificación de los soldados, se confeccionaban unos padrones para el alistamiento, que incluían la relación de los mozos a una edad específica, según la normativa legal de la época, y que estaban elaborados, de manera escrupulosa, por los alcaldes de barrio, con información previa de los registros civiles, noticias facilitadas por los curas párrocos tomadas de los libros bautismales y otros antecedentes necesarios. Padrones que, en caso de distritos municipales con mucho vecindario, quedaban divididos en secciones o distritos para todas las operaciones pertinentes del reemplazo. Del alistamiento en estos padrones quedaban excluidos los que en el reemplazo anterior habían redimido la suerte de soldados por medio de sustituto o de retribución pecuniaria (art. 49 de la Ley de 1856), y que tiene vigencia hasta 1912 (art. 4 de la Ley de 1912). Sin embargo, he de señalar que la participación de estos mozos redimidos en el conjunto de los alistados es bien escasa e insignificante para el municipio de Murcia, lo que no va a presuponer modificación alguna importante en la tendencia de la estatura mostrada a lo largo de este período. Hacia 1915, la relación de «mozos de cuota» para la provincia de Murcia era de 1,1 por $100^{8}$, a diferencia de otras provincias (Gui-

'Martínez Carrión (1981).

- Gómez Mendoza y Pérez Moreda (1985), p. 19. 
púzcoa, Madrid, Barcelona, por ejemplo) que sobrepasaban el 10 y 15 por 100 ; confirmando, de esta manera, la escasa proporción de familias que en Murcia pagaban una cantidad de 1.000 ó 2.000 pesetas con la mera finalidad de reducir la permanencia en filas de sus hijos a un período relativamente corto.

Estas estadísticas militares se conservan, por lo común, en los archivos municipales y, en algunos casos, en los respectivos archivos históricos provinciales. Año a año, los expedientes de reemplazo contienen, además de los datos referidos a medidas antropométricas (estatura, peso y capacidad torácica) ${ }^{9}$, una valiosa información sobre el estado de salud y morbilidad de los mozos, su profesión, nivel de alfabetización, índices de movilidad geográfica y hasta información, en algunos casos muy detallada, acerca de la situación socioeconómica de la familia. La riqueza documental de esta fuente para el estudio de los niveles de vida salta, pues, a la vista; tan sólo contrapesada por lo fragmentario y discontinuo de algunos datos en la documentación conservada. La utilidad de estas fuentes para el estudio de las condiciones sociales, y particularmente para la estimación de la morbilidad de las clases trabajadoras, sobre todo a través de la relación de personal no apto e incapacitado para el servicio militar, fue sugetrida relativamente temprano ${ }^{10}$, si bien sus resultados y algunas de sus conclusiones han aparecido recientemente ${ }^{11}$.

Sin embargo, ha sido la estatura el indicador que más ha llamado la atención entre los historiadores económicos, y el mejor aprovechado, tal vez, en relación con otras variables socioeconómicas. Ciertamente, en nuestro caso, ha sido la talla de los mozos el único dato que he manejado, puesto que se mantiene regularmente para el período histórico escogido, lo que ha posibilitado la estimación de su evolución anual. Datos sobre el peso y la capacidad torácica aparecen y desaparecen, sobre todo en el primero, a partir de 1912, y otra información sobre alfabetización, profesión, morbilidad y movilidad de los mozos aparece fragmentada e irregular, dependiendo en cada caso de la escrupulosidad de los escribanos de turno y funcionarios de la época correspondiente. Para este trabajo he recogido la talla de 39.142 mozos, que las fuentes me han permitido entre 1860 y 1930 , circunscritos al municipio de Murcia, que englobaba en este período a la ciudad-capital, distribuida en 12 distritos parroquiales; 33 núcleos de la buerta, cubriendo una amplia zona del regadío murciano, y la población de 17 pedanías repartidas en el campo, o zona de secano ubicada en el denominado campo de Cartagena.

- Los datos recogidos para este trabajo presentan información de la estatura en todo el período, con la excepción de los últimos años, entre 1926-27 y 1930, que aparecen irregularmente sin especificar el lugar de residencia de los mozos. El conjunto de la información militar y los datos se encuentran repartidos en más de 200 legajos del Archivo Municipal de Murcia.

10 Hobsbawn (1977), p. 159, y (1979), p. 94.

1 Floud (1985). 
Dada la composición media anual del conjunto de mozos del término municipal murciano entre 1860 y $1910(\bar{x}=810)^{12}$, pueden estimarse conclusiones válidas a través de los resultados obtenidos, puesto que la muestra es bastante significativa, dado el abundante número de observaciones y la calidad de los datos reseñados y habida cuenta de la escrupulosidad con que se tallaba a los mozos. A partir de 1912 y hasta 1930, encontramos dificultades para la estimación de la evolución anual de la estatura media, debido a la escasa relación aparecida por presunta desaparición de las fuentes para algunos años y la fragmentación hallada en otros. El total de mozos observados para el período de 1912 a 1930 ha sido de 3.297 , que, aun siendo representativos, sus resultados deben medirse con cierta cautela.

Otra dificultad pudiera venir de las modificaciones que se suceden a lo largo del período escogido para la edad reglamentaria de incorporación a filas y el momento del tallaje. Ciertamente, la homogeneidad de los datos y de las series temporales puede quedar empañada por los inconvenientes de las oscilaciones de la edad de entrar en caja. La Ley de 1856 fijaba la edad para el alistamiento en los que tenían cumplidos los 20 años y cumplido los 21 el día 30 de abril, inclusive, del año en que se verifica el alistamiento (art. 13 de la Ley del 5 de enero de 1856). Casi veinte años más tarde, la edad seguía fijada hacia los 20 años de edad, comprendiendo en el alistamiento los mozos que «sin llegar a los 21 años hayan cumplido o cumplan 20 años desde el 1. de enero al 31 de diciembre del año en que se ha de verificar el sorteo", y, finalmente, aquellos mozos que, excediendo de la edad reglamentaria sin haber cumplido los 35 años, no fueron comprendidos por cualquier motivo en ningún alistamiento ni sorteo de los años anteriores (art. 17 de la Ley de 28 de agosto de 1878). Siete años más tarde, la edad de incorporación a filas se rebajaba un año de edad (art. 26 de la Ley de 11 de julio de 1885), quedando fijada a los 19 años; así hasta 1912, en que de nuevo se establece la edad de incorporación a filas cumplidos los 21 años durante el año del alistamiento (art. 32 de la Ley de 27 de febrero de 1912). Por tanto, en los cambios de tendencia mostrados en la estatura a lo largo del período histórico escogido, entre 1860 y 1930 , debo tener presente la modificación de la edad reglamentaria para el alistamiento y la incorporación a filas, puesto que el período de crecimiento humano se prolonga hasta casi los 25 años.

Finalmente, quisiera hacer unas observaciones a las series que las fuentes impresas presentan desde 1857. Me estoy refiriendo a los Anuarios Estadisticos de España, publicados por distintas entidades oficiales y que reseñan datos de estaturas de los españoles desde 1858 a 1863 y desde 1915 en adelante.

${ }^{12}$ No se reflejan los datos, por no haberlos encontrado, de los años siguientes: 1861, $1868,1870-71,1873-74,1875,1900$ y 1906 . Tampoco se reflejan los datos del campo entre los años 1901 a 1911 . Y a partir de esa fecha los datos son fragmentarios e irregulares. 
En primer lugar, no presentan evaluaciones de alturas medias en los períodos correspondientes, lo que dificulta su estudio comparativo entre escalas locales, comarcales y la evolución anual a escala nacional, si no es a través de medias aritméticas ponderadas, tal y como han mostrado Gómez Mendoza y Pérez Moreda para España y sus provincias durante el primer tercio del siglo $\mathrm{xx}^{13}$. En efecto, los datos de estaturas vienen presentados en forma de distribución de frecuencias, en grupos de mayor a menor altura. La segunda observación viene en el siguiente sentido: mientras en el período de 1858-1863 aparecen las estaturas agrupadas de todos los mozos llamados a reclutamiento y alistamiento, en concreto de los mozos presentados, en el período de 1915 a 1929 no se tienen en cuenta, sin embargo, los mozos «no aptos» para el servicio militar, entre los que se cuentan aquellos que miden menos de $1,54 \mathrm{~m}$, por lo que su utilización requiere cierta prudencia y confrontación con resultados de ámbito local y comarcal como los que a continuación se presentan.

\section{Implicaciones demográficas y económicas en la evolución de la estatura}

La estimación evolutiva de la estatura media de los adultos varones en torno a la edad de 19-21 años la muestro en la tabla 1 y gráfico 1 . Junto a la estatura media de los mozos del municipio de Murcia presento, además, la evolución de las tallas medias que he evaluado para el área urbana y rural, distinguiendo en esta última, en la medida que las fuentes me lo han permitido, entre mozos de poblaciones de huerta y mozos de poblaciones de campo. Y la primera impresión que nos muestran sus resultados es la existencia de varios ciclos. El primero se establece entre 1860 y 1875 , de ligera tendencia al alza; el segundo, de 1875 a 1895 , se caracterizaría por una fuerte caída, sobre todo a la altura de comienzos de los años noventa; finalmente, el tercero, de 1895 a 1910 , refleja una cierta recuperación, que se muestra rápida, de los niveles alcanzados treinta años atrás y un decidido crecimiento hacia finales de la primera década del siglo xx. La etapa de 1911 a 1930 , con el inconveniente de los escasos datos evaluados para algunos años, permite, no obstante, mostrar una pequena inflexión al final de la segunda década del siglo y el mantenimiento de los niveles alcanzados a comienzos de nuestra centuria para la década de los años veinte, con cierta tendencia al aumento en los años cercanos a la década de los treinta. Resultados que van a estar vinculados, como se muestra a lo largo de estas páginas, a las fases de crecimiento, crisis y expansión de la agricultura mediterránea, que caracteriza a la región que nos ocupa, junto a la importancia de componentes demográficos y ambientales específicos de esta comarca.

is (1985), pp. 29-64. 


\section{TABLA 1}

Estimación de la estatura media a la edad de 19-21 años

\begin{tabular}{|c|c|c|c|c|c|}
\hline & Ciudad & Huerta & Campo & Municipio & $\begin{array}{c}\text { Muestra } \\
\text { (N) }\end{array}$ \\
\hline $\begin{array}{lllllll}1860 & \ldots & \ldots & \ldots & \ldots & \ldots & \ldots \\
1865 & \ldots & \ldots & \ldots & \ldots & \ldots & \ldots \\
1869 & \ldots & \ldots & \ldots & \ldots & \ldots \\
1875 & \ldots & \ldots & \ldots & \ldots & \ldots & \ldots \\
1880 & \ldots & \ldots & \ldots & \ldots & \ldots & \ldots \\
1885 & \ldots & \ldots & \ldots & \ldots & \ldots & \ldots \\
1890 & \ldots & \ldots & \ldots & \ldots & \ldots & \ldots \\
1895 & \ldots & \ldots & \ldots & \ldots & \ldots & \ldots \\
1899 & \ldots & \ldots & \ldots & \ldots & \ldots & \ldots \\
1905 & \ldots & \ldots & \ldots & \ldots & \ldots & \ldots \\
1910 & \ldots & \ldots & \ldots & \ldots & \ldots & \ldots \\
1912 & \ldots & \ldots & \ldots & \ldots & \ldots & \ldots \\
1920 & \ldots & \ldots & \ldots & \ldots & \ldots & \ldots \\
1922-25 & \ldots & \ldots & \ldots & \ldots & \ldots \\
1926-30 & \ldots & \ldots & \ldots & \ldots & \ldots\end{array}$ & $\begin{array}{l}1,628 \\
1,627 \\
1,642 \\
1,642 \\
1,633 \\
1,626 \\
1,627 \\
1,617 \\
1,645 \\
1,640 \\
1,661 \\
1,656 \\
1,643 \\
1,652 \\
-\end{array}$ & $\begin{array}{l}1,592 \\
1,601 \\
1,602 \\
1,604 \\
1,595 \\
1,600 \\
1,597 \\
1,579 \\
1,599 \\
1,620 \\
1,630 \\
1,637 \\
\overline{1,636} \\
1,639\end{array}$ & $\begin{array}{l}1,601 \\
1,588 \\
1,611 \\
1,613 \\
1,597 \\
1,604 \\
1,580 \\
1,568 \\
1,597 \\
= \\
- \\
\overline{1} \\
1,632\end{array}$ & $\begin{array}{l}1,599 \\
1,604 \\
1,609 \\
1,614 \\
1,603 \\
1,606 \\
1,602 \\
1,588 \\
1,608 \\
1,625 \\
1,638 \\
1,644 \\
1,639 \\
1,641\end{array}$ & $\begin{array}{r}850 \\
646 \\
277 \\
585 \\
795 \\
1.774 \\
982 \\
1.016 \\
1.028 \\
891 \\
905 \\
438 \\
224 \\
955 \\
1.738\end{array}$ \\
\hline
\end{tabular}

FUENTE: Expedientes de Reemplazo. Elaboración propia.

En relación a los ciclos de la estatura mostrados en la segunda mitad del siglo XIX, conviene empezar señalando la evolución de su valor medio. Para el conjunto de los mozos del término municipal murciano, la talla media en 1860 era de $1,599 \mathrm{~m}(N=850)$, subiendo, quince años más tarde, en 1875 , un centímetro y medio $(\bar{x}=1,614 ; N=585)$, y desde esta fecha hasta 1895 $(\bar{x}=1,588 ; N=1.016)$, de clara tendencia a la baja, la talla media cae $2,6 \mathrm{~cm}$. Cotejando las tallas medias de los años 1860,1875 y 1895, así como las medias evaluadas cada cinco años para este período, deben extraerse algunas conclusiones que, a mi juicio, tienen relación con la coyuntura económica y demográfica y las repercusiones específicas que operan en la comarca de Murcia.

En primer lugar, cabe señalar cómo el proceso de expansión agraria y crecimiento económico en general, que opera en tierras murcianas durante las décadas centrales del siglo $\mathrm{xIx}^{14}$, debió tener repercusión en los niveles de vida de la población, a través de una ligera mejoría en las pautas de nutrición y consumo alimenticio. Debió incrementarse la cantidad de los alimentos que tradicionalmente consumían, incorporando otros nuevos y en cantidad superior a la mostrada en la primera mitad del siglo xix. A mediados de siglo,

\footnotetext{
14 Pérez Picazo y Lemeunier (1984), pp. 307 y ss.
} 


\section{GRAFICO 1}

Evolución de la estatura media en Murcia, 1860-1930
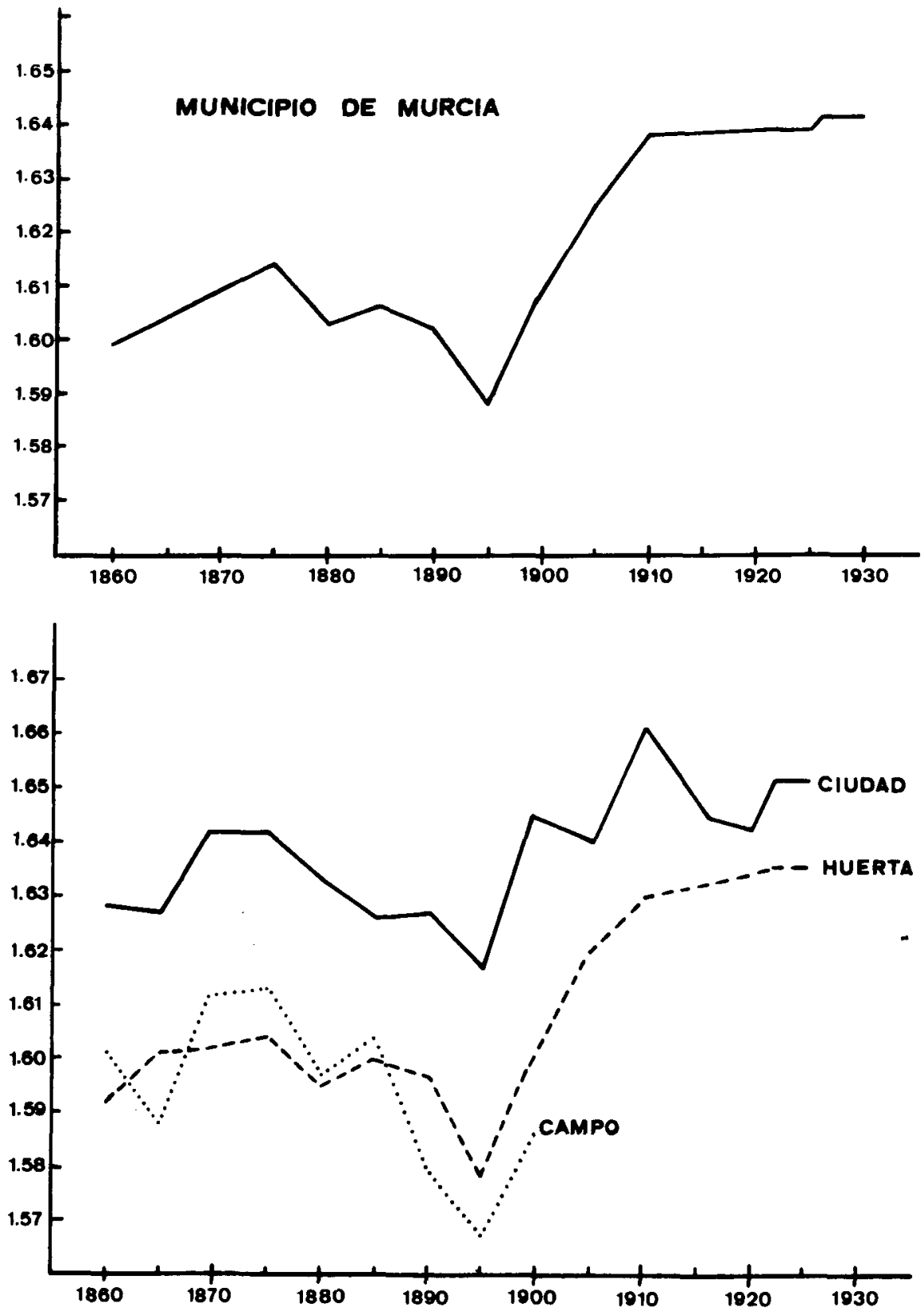
resultados de una encuesta agraria a escala nacional ${ }^{15}$ muestran cómo la dieta alimenticia de los jornaleros agrícolas en Murcia estaba compuesta, básicamente, por pan de cebada y maíz, puche de cebollas, ajos, pimientos y otras verduras, aceite y patatas. Aunque supone una composición de nutrientes poco diversa, destaca la cantidad de hortalizas, entre ellas la patata, que el jornalero consume diariamente, en relación a períodos históricos anteriores. Se ha de tener en cuenta que el cultivo y consumo de este preciado artículo alimenticio, entre la masa jornalera de la segunda mitad del siglo xix, estaba orientado en los siglos xvir y xviII para la ganadería de cerda, especialmente. De otra parte, destaca la ausencia de carne fresca en el consumo diario, que va a ser constante en la dieta alimenticia que se establece en la segunda mitad del siglo xix. En la ciudad; y sobre todo en algunos de sus barrios más céntricos, y por el peso de su renta, el consumo de proteínas animales debía ser más generalizado. No obstante, en la huerta, como en las poblaciones del campo, se va extendiendo el consumo de salazones, y en particular el consumo de bacalao, que suple la deficiencia de proteínas que contiene la carne fresca.

Pero, pese a las diferencias en el consumo diario alimenticio y en la nutrición entre sectores rural y urbano, que no es sino el reflejo de las condiciones económicas y hábitos de consumo entre las diferentes clases sociales, se pueden apreciar síntomas que nos muestran una mejora, por pequeña que fuera debe destacarse, que repercute en las pautas de consumo alimenticio hacia mediados del siglo xIx. Al incremento de patatas y hortalizas debo añadir el aumento de las legumbres y, en concreto, el incremento de consumo de arroz, garbanzos y alubias o habichuelas. Ciertamente, la construcción del ferrocarril hacia 1862 supone un claro incentivo para la producción y comercialización de frutas y hortalizas, además de favorecer los intercambios entre productos básicos de consumo. El aumento de la producción de patatas, generalizado durante la primera mitad del siglo $\mathrm{xIx}^{16}$, y de su consumo hacen de ella el componente nutritivo por excelencia de la dieta alimenticia entre los sectores populares a lo largo de la segunda mitad del siglo xIX. Junto a la patata, otras hortalizas y legumbres ya señaladas que suponen una ligera mejora de la nutrición, dado su aporte vitamínico y riqueza en sustancias minerales (fósforo, hierro, calcio), necesarias para el desarrollo óseo y muscular en el período de crecimiento. Consecuentemente, el ligero incremento de la talla media entre 1860 y 1875 puede estar, en parte, relacionado con ello. Con todo, la talla evaluada sigue siendo de las más baias de España a la altura de $1860^{17}$; siendo, a su vez, el país que menores tallas presenta de la Europa

1s Moral Ruiz (1979), pp. 113-114.

16 Anes (1970), p. 150, y Pérez Moreda (1980), p. 413.

17 Véase, en comparación con otras provincias, en Gómez Mendoza y Pérez Moreda (1985), p. 63. 
occidental, en la misma escala que otras regiones mediterráneas ${ }^{18}$, esto traduce el estado de alimentación y salud de la población que nos ocupa y, en definitiva, de su nivel de vida. Reflejo, por otra parte, de las distintas condiciones de nutrición, la talla media de los mozos de la ciudad se presenta más elevada que la de la huerta y el campo, por encima de los $2 \mathrm{~cm}$, e incluso $3 \mathrm{~cm}$, a lo largo de este período.

El cambio de coyuntura económica se manifiesta hacia 1880 y se prolonga hasta 1895, siendo conocido este período por los efectos de la «depresión agraria». Los bajos rendimientos agrícolas, consecuencia del agotamiento de la puesta en cultivo de tierras de escasa calidad y la falta de recursos hidráulicos en la zona de secano, la caída de los beneficios debido al alza de los costes de producción en las explotaciones agrícolas y la caída de los precios agrícolas ${ }^{19}$, provocan la quiebra económica de numerosas explotaciones agrícolas basadas en el sistema extensivo. Si a ello añadimos el impacto de las sucesivas crisis de subsistencias, que en la huerta de Murcia se manifiestan a través de prolongadas sequías y fuerte presencia de inundaciones provocadas por riadas en los años ochenta $(1879,1884,1888,1890)$, se comprende lo diezmada que quedó la producción agrícola y ganadera, inclusive, durante los años ochenta y primeros de los noventa del siglo pasado. Las referencias a pérdidas de ganado por enfermedad en este período son extraordinarias. En el campo, además de la sequía, la producción de cereales no se sostiene por la prolongación de la tendencia a la baja de los precios de los cereales desde 1884 , que no se recuperan hasta $1897^{20} ; \mathrm{y}$, aunque no descendieron bruscamente, la acumulación anual de los costos de producción a la altura de los años noventa debió producir una fuerte caída de la tasa de beneficios, agravada aún más por la fuerte competencia de los precios de los cereales extranjeros y el elevado costo de los envíos por ferrocarril. A la actitud de abandono de las tierras por parte de algunos pequeños propietarios le siguió el descenso de la demanda de trabajo, con el consiguiente aumento de los índices de desempleo.

En estas condiciones económicas desfavorables se incrementa la corriente migratoria hacia el exterior. La década de los años ochenta supuso la fase de mayor incremento de murcianos en dirección a las costas argelinas. En el bienio 1885-86, el promedio anual, en este caso a escala provincial, se cifraba en 1.681 emigrantes, y aún en el quinquenio de $1891-95$ lo era de 1.416 emigrantes ${ }^{21}$. Ya en la década de los años noventa, cuando se constata un descenso progresivo de emigrantes murcianos hacia Argelia, se incrementa, aún con poco pulso, el número de murcianos en dirección hacia Cataluña.

\footnotetext{
18 Floud (1983).

${ }^{19}$ Garrabou y Sanz (1985), pp. 179 y ss.

${ }^{20}$ Pérez Picazo (1979), p. 166.

21 Vilar Ramírez (1975), pp. 107-109.
} 
Y justamente con el paro y la emigración las condiciones de alimentación no debieron mejorar, sino más bien todo lo contrario, debido a la caída de los índices de producción agraria y consecuente caída de rentas, sobre todo en la agricultura y ganadería y sectores productivos dependientes de éstas. Las estadísticas de producción de cabezas de ganado a escala comarcal, más aún provincial, muestran una caída del volumen de ganado en consonancia con la tendencia a la baja que han mostrado las estadísticas nacionales ${ }^{22}$. Si hasta entonces el consumo de carne y proteínas animales era bien escaso, entre 1880 y 1895 la alimentación de familias jornaleras se reduce, según diversos informes, al consumo de verduras «salvajes» (collejas, acelgas; a lo sumo, espárragos), migas, hortalizas y algunos salazones. Hacia 1883, el alcalde de turno de la ciudad, Eduardo Riquelme Figueras, señalaba cómo los habitantes de la huerta se alimentaban de "pan de maíz y cebada, de legumbres y hortalizas y únicamente comen carne en las grandes festividades y en las épocas de recolección los años de abundante cosecha" ${ }^{23}$. Años más tarde, la situación agraria empeoraba considerablemente.

Si las condiciones de nutrición no eran favorables, tampoco lo fueron las condiciones de salud y morbilidad, sobre todo en el área rural. El incremento de la tasa de mortalidad general descansaba sobre el aumento de las enfermedades infecto-contagiosas de tipo infantil y juvenil y el incremento de las enfermedades relacionadas con el aparato digestivo: enteritis, gastroenteritis, fiebres tifoideas, que estaban relacionadas con las malas condiciones de salubridad e higiene de la población y la ingestión de alimentos en mal estado de conservación. El paludismo, ya endémico en ciertos sectores de la huerta, incrementa su morbilidad a partir de 1880 hasta casi finales de siglo, dejando amplias secuelas entre la población adolescente. El debilitamiento que se producía por la frecuencia de sus fiebres ocasionaba una caída de la oferta de mano de obra en los trabajos agrícolas que acentuaba, aún más, el carácter restrictivo de la producción agraria en áreas muy localizadas, y ello posibilitaba una menor capacidad de componentes nutritivos, con el consiguiente deterioro de las naturalezas fisiológicas. Sobre la relación paludismo y encanijamiento volveré más adelante.

En general, el estado de la nutrición entre 1880 y 1895 fue bien precario, siendo escaso, y en algunos periodos nulo, el consumo de carne, ahora sustituido por salazones, pero todavía a escalas muy pequeñas. Puede señalarse, por tanto, una pérdida del poder nutritivo para una gran mayoría de la población, sobre todo entre aquélla de los sectores populares. El deterioro de las condiciones de alimentación y nutrición y de las condiciones de salubridad y morbilidad de la población se corresponde en este período con la caída de

2 Grupo de Estudios de Historia Rural (en adelante, GEHR) (1979, 1980).

${ }^{23}$ Cítado en Pérez Picazo (1979), p. 25. 
las tallas medias de los mozos. En conjunto, la talla media hacia 1875, establecida en $1,614 \mathrm{~m}$, pierde veinte años más tarde $2,6 \mathrm{~cm}$, cifrándose en $1,588 \mathrm{~m}$ para el año 1895 . Comparando las tallas medias de áreas diferentes, constatamos cómo el campo muestra la caída más pronunciada al final del período depresivo considerado en la década de los años ochenta y primeros de los noventa, estimándose en $4,5 \mathrm{~cm}(1875, \bar{x}=1,613 ; 1895, \bar{x}=1,568)$, mientras que la ciudad $(1875, \bar{x}=1,642 ; 1895, \bar{x}=1,617)$ y la huerta $(1875$, $\bar{x}=1,604 ; 1895, \bar{x}=1,579$ ) presentan, aun con alturas diferentes, una caída similar, estimada en $2,5 \mathrm{~cm}$. Si observamos más detenidamente, la mayor parte de la caída para el área del campo corresponde al decenio 1885-1895, al perder en este período $3,6 \mathrm{~cm}^{24}$. En la huerta, para el mismo periodo, la caida se cifra en $2,1 \mathrm{~cm}$, mientras que en la ciudad las pérdidas evaluadas son tan sólo de $0,9 \mathrm{~cm}$. Más aún, si hasta entonces las tallas medias estimadas eran, por lo general, más favorables a los mozos del área del campo o del secano, a partir de 1885 los mozos de la huerta presentan una altura ligeramente superior a la de los del campo. Por estos resultados podría concluirse un deterioro de las condiciones de vida, en concreto de salud y alimentación, en sectores dependientes de economías agrícolas extensivas, donde la producción era básicamente cerealera ${ }^{25}$, como parecen mostrar las poblaciones del campo, y, en general, un deterioro de los niveles de vida que afecta principalmente al área rural, compuesta básicamente de jornaleros y pequeños propietarios, y a sectores populares establecidos en los barrios periféricos de la ciudad.

Sin embargo, en la explicación de la caída de la talla media de los mozos en las últimas décadas del siglo xix debo admitir la entrada en juego de otros factores, además de los señalados, puramente económicos y demográficos o simplemente ambientales. En concreto, me estoy refiriendo a los factores polítivos que posibilitaron la modificación de la edad reglamentaria para incorporación a filas hacia 1885 . Es a partir de este año cuando se rebaja un año la edad a dicha incorporación, pasando de 20 a 19 años la edad del tallaje de los mozos para su definitiva declaración y clasificación de soldados. La cuestión colonial, tanto en Cuba como en Filipinas, requería cada vez más un mayor contingente de soldados, que se acentuará bien entrada la década de los años noventa. Por otra parte, el aumento de prófugos y el elevado número

${ }^{24}$ La severa caída, en momentos de crisis económica, no debe sorprendernos. Casos similares se han dado, por ejemplo, en el sur de Flandes, para las décadas centrales del siglo xIx, donde la crisis de la industria del lino a lo largo de las primeras décadas del siglo xIx permitió un proceso de desindustrialización que empobreció la dieta alimenticia de los artesanos y jornaleros hacia 1840-1850: la estatura media pasó de $1,65 \mathrm{~m}$ a comienzos del siglo xIx a $1,58 \mathrm{~m}$ en el segundo cuarto de siglo. Véanse Vanderbroeke (1981) y Scholliers y Vanderbroeke (1982), pp. 34-35.

${ }^{25}$ Sobre los efectos de la crisis finisecular en la agricultura extensiva, Garrabou (1975). 
de mozos «exentos», dado su deficiente estado de salud en estos años, debió provocar el adelantamiento de la edad de incorporación a filas en un momento, además, en que se acentúa la presión y exigencias militares. $Y$, con los factores políticos y militares, destacar otro de matiz claramente social: la premonición de guerra colonial, ya al principio de los años noventa, y su definitiva declaración en Cuba en febrero de 1895, pudo incrementar el número de mozos redimidos, es decir, aquellos que por sustitución con otro mozo o la entrega de cierta cantidad de dinero en metálico quedaban automáticamente excluidos del servicio militar. Naturalmente, la extracción social de los mozos redimidos se correspondía con las clases sociales de mayor renta. En este sentido, si admitimos la correlación existente entre estaturas elevadas y grupos sociales de mayor renta, dado su mejor estado nutritivo, he de suponer que a mayor incremento de mozos redimidos ha de corresponder una talla media más baja, en tanto que quedan excluidos aquellos mozos mejor alimentados y, por tanto, más altos, como consecuencia de su redención. Hechas, pues, estas observaciones, cabe preguntarse por el impacto y la dimensión que ambos factores ejercieron en la evolución de la estatura de los mozos a partir de 1885 .

En primer lugar, las noticias referidas a mozos redimidos a lo largo del período son irrelevantes, siguiendo la información manejada en los reemplazos militares, aunque pudieran encontrarse en otro tipo de fuentes aún no conocidas. Con todo, y por el peso de la estructura social en Murcia, los casos de mozos redimidos debieron ser escasos y poco significativos en el conjunto de los mozos tallados, más aún si tenemos en cuenta que un considerable volumen de mozos eran jornaleros y procedian del área rural. Tampoco se ha visto una caída importante entre los mozos tallados para el periodo anterior y durante la guerra colonial cubana, entre 1895-1898. Más bien todo lo contrario, pues justamente el año de iniciarse la guerra, en 1895 , se incrementa el número de mozos en el reemplazo correspondiente. En segundo lugar, y habida cuenta de una cierta homogeneidad en el volumen y en la naturaleza social y económica de los mozos tallados para el período de 1885 y 1912, etapa también homogénea por la edad de los tallados en torno a los 19 años, cabría haberse registrado un cambio de tendencia de la estatura hacia 1885-86, momento en que se modifica la edad reglamentaria de incorporación a filas, y, en todo caso, en los años 1895-98, período de la guerra colonial, en el supuesto hipotético de un porcentaje importante de mozos redimidos que por ahora desconocemos. Cambio de tendencia que se traduciría en una leve caída de la estatura media en esos momentos. Sin embargo, aquél se inicia antes de 1885 y, sobre todo, se produce entre 1890 y 1895 . En efecto, la caída más importante de las tallas medias se opera en este quinquenio, de manera extraordinaria en las poblaciones del campo y la huerta, que, a mi 
juicio, debe relacionarse con la caída del poder alimenticio, por la malnutrición acumulativa que anualmente se viene padeciendo desde mediados de los ochenta, ya con los efectos de la crisis agraria, y la intensidad de las enfermedades de carácter infeccioso que vienen provocando estados de raquitismo y encanijamiento entre la población infantil y adolescente, en concreto del paludismo. Aunque no se descarta la incidencia de los factores sociales y políticomilitares enunciados, que, sin embargo, considero de menor entidad.

Otro procedimiento me permite corroborar tales observaciones. Mediante el análisis de distribución de frecuencias porcentualmente agrupadas, se detecta una relación bastante elevada de mozos que no superaban el $1,50 \mathrm{~m}$ durante la década de los años noventa. En la tabla 2 presento los valores relativos distribuidos en cuatro grandes grupos según su altura, mientras que en la tabla 3 muestro los valores correspondientes de los que sobrepasaban el $1,70 \mathrm{~m}$ y los que no superaban el $1,50 \mathrm{~m}$. Cotejando los resultados de los períodos quinquenales, constato un incremento de los valores relativos de los mozos menos desarrollados físicamente entre 1885 y 1899 . Aun teniendo en cuenta el cambio, en 1885 , de la edad reglamentaria para el tallaje de los mozos, la evolución anual en este período no hace sino confirmar algunas conclusiones ya señaladas: la crisis agraria, y consecuentemente el deterioro de las condiciones de nutrición, así como el enrarecimiento de las condiciones ambientales, con el consiguiente deterioro de la salud e higiene, afectó con más dureza a las poblaciones del campo y sectores relacionados con la economía extensiva de cereales, y en general a la población rural, como prueba la menor relación de mozos «raquíticos» en el área urbana. Así, en 1895, el 26,8 por 100 de los mozos del campo no alcanzaban el metro y medio, relación que era de 18,8 por 100 en la huerta y tan sólo de 9,9 por 100 en la ciudad. A la vista de los valores relativos, los porcentajes más elevados corresponden al quinquenio de 1890-94, donde el 15,4 por 100 de los mozos rurales pueden considerarse poco desarrollados físicamente y deficientemente nutridos, mientras que la relación mostrada en la ciudad era de un 5,9 por 100 .

Si estos valores los comparamos con los del quinquenio 1860-64, se constata la degradación de las condiciones de vida que se produce en las dos últimas décadas del siglo xix: los mozos rurales presentan una relación de 6,4 por 100 en ese período, mientras que los mozos urbanos muestran la irrelevante proporción de 0,8 por 100 . La evolución de estos valores se corresponde en sentido inverso a los valores presentados por los mozos que superan el $1,70 \mathrm{~m}$, que cabría considerarlos «bien alimentados». En este sentido, los mozos «altos» del área rural mostraban en $1890-94$ un valor del 4,6 por 100 , mientras que en $1860-64$ lo mostraban en 5,3 por 100 ; entre tanto, los mozos de la ciudad presentaban para las mismas fechas, respectivamente, valores del 12,5 y 14,4 por 100 . Los resultados me permiten detallar algo más. De un 


\section{GRAFICO 2}

Relación proporcional de mozos altos (A) y mozos poco desarrollados (B) en el municipio de Murcia, 1860-1925

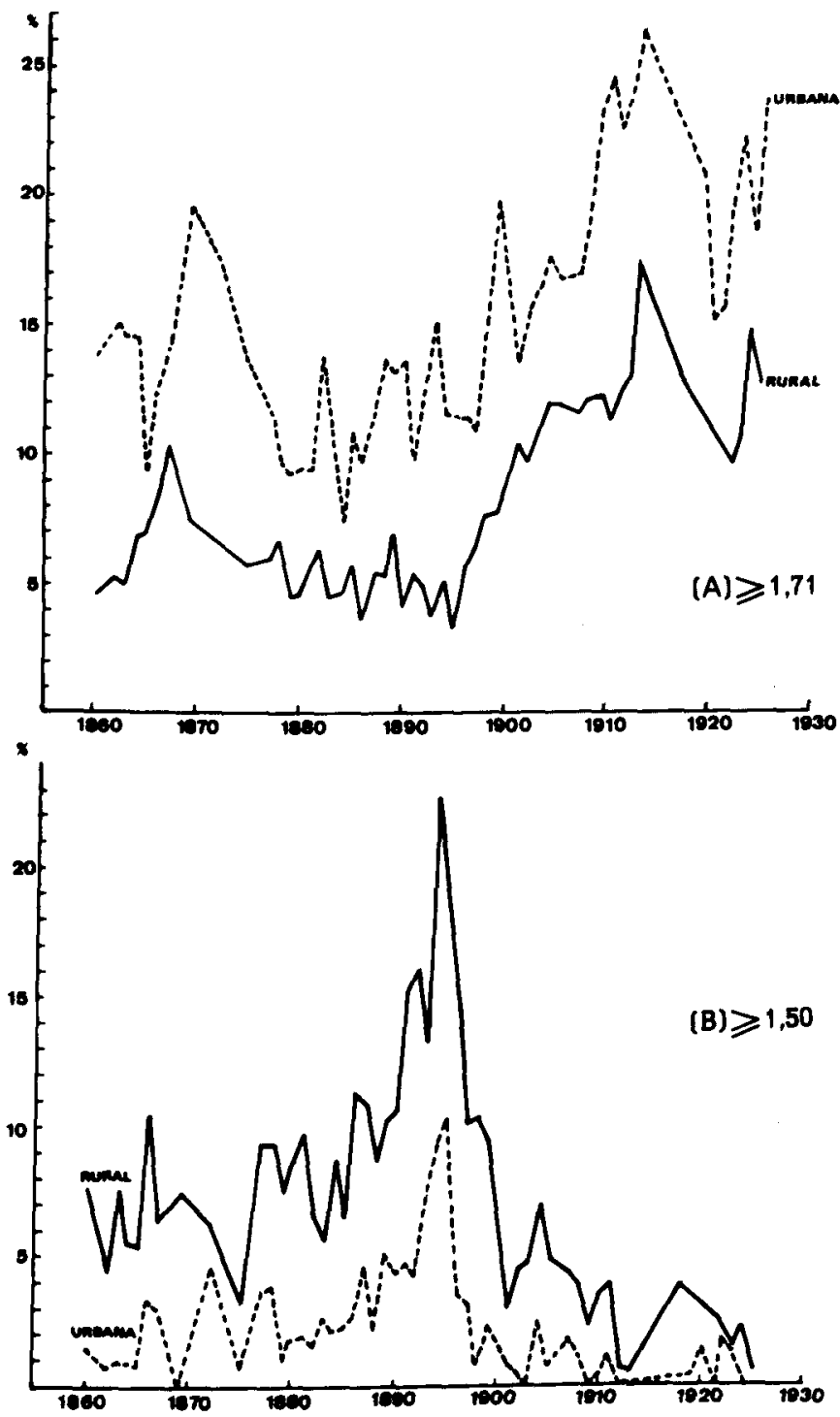

Furnte: Expedientes de Reemplazo. 


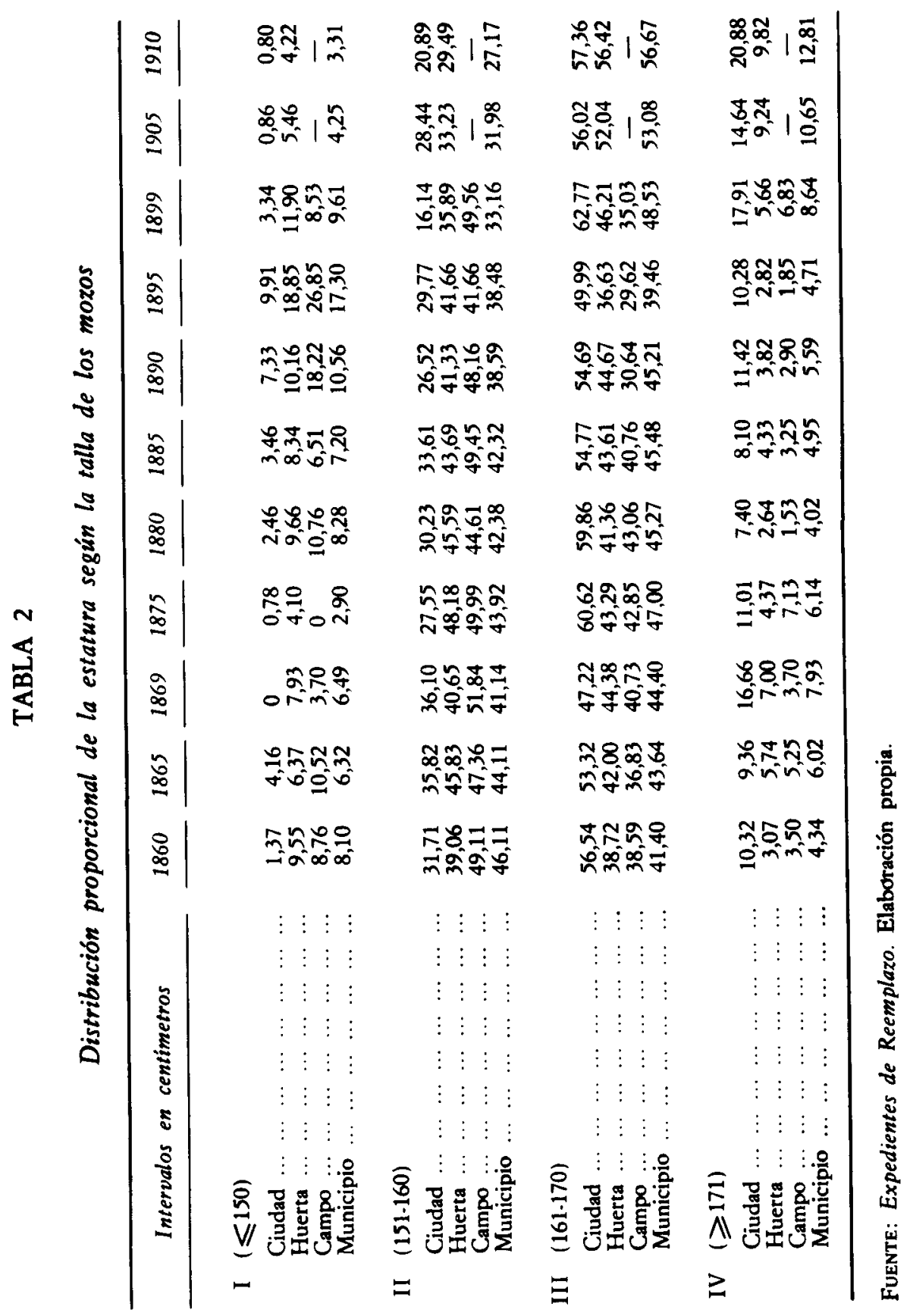




\section{GRAFICO 3}

Relación proporcional de los mozos altos $y$ poco desarrollados para el municipio de Murcia. 1860-1930

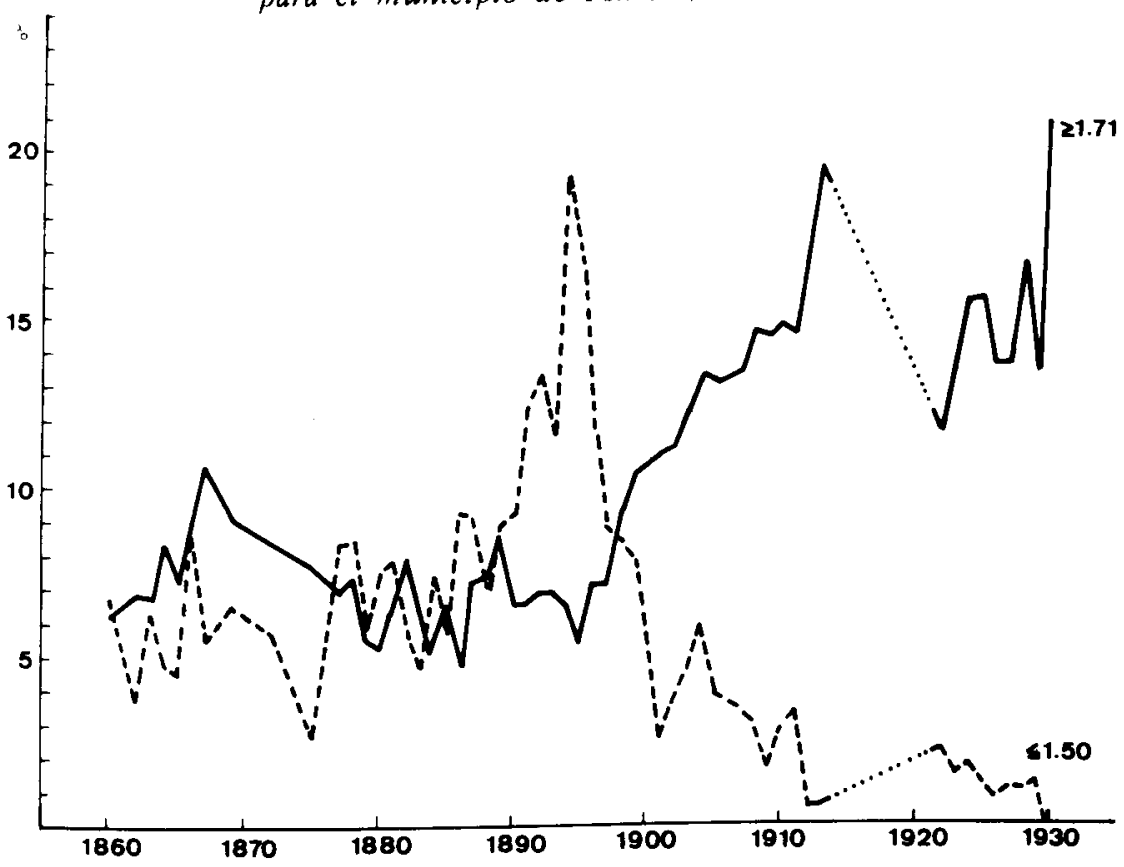

FUente: Expedientes de Reemplazo.

lado, el empeoramiento de las condiciones de nutrición y salud entre 1875 y 1898 , cuyo momento más álgido corresponde al quinquenio de 1891-1895, y que, como ya señalé, recae sobre el nivel de vida de los jornaleros agrícolas. De otro, se constata por la tendencia del grupo de «altos» un aumento casi ininterrumpido de sus valores relativos desde 1885, tras el bache sufrido entre 1875-1884, que parece mostrar la existencia de un sector social minoritario que, pese a la crisis agrícola y deterioro de las condiciones ambientales, permanece en un nivel que podría considerarse «bien alimentado». En efecto, la proporción de mozos «altos» no disminuye en la ciudad entre 1890-1894, como sí ocurre en la zona rural - de ahí la importante caída de la talla media en este área-, sino todo lo contrario, va aumentando. Factor que debo vincularlo a las condiciones de nutrición y salud del grupo de mozos relacionados con sectores artesanales, tal vez comerciales, y profesionales depen- 


\section{TABLA 3}

Distribución de la estatura de los mozos según su talla en el sector rural y urbano

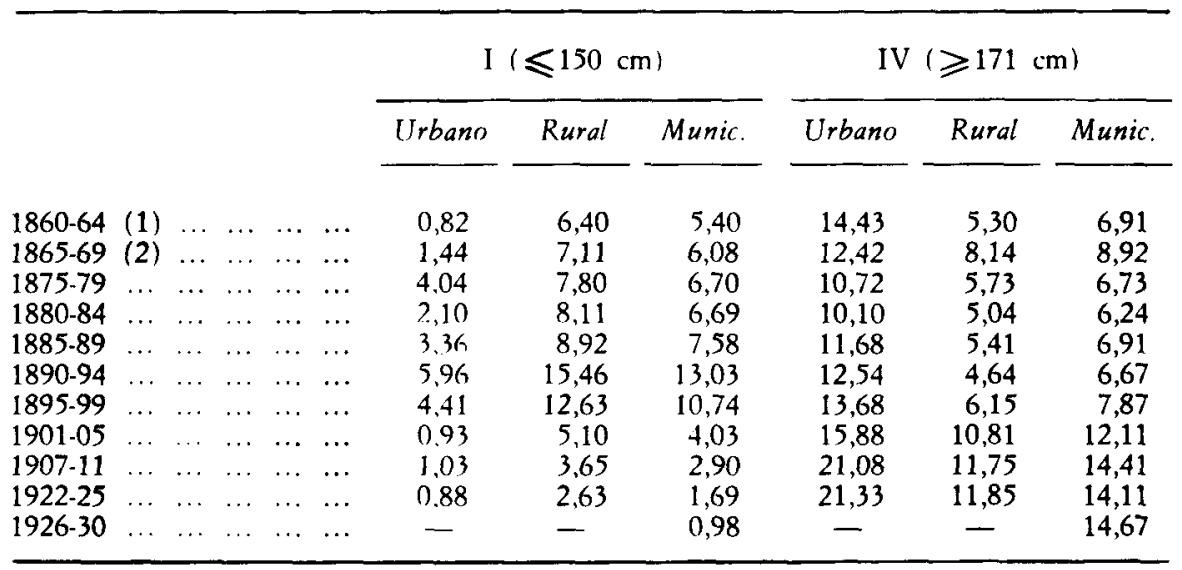

(1) No se incluye 1861 .

(2) Idem, 1868.

Fuente: Expedientes de Reemplazo. Elaboración propia.

dientes del aparato burocrático-administrativo, que no dependen tanto de las fluctuaciones de la renta de los trabajos agrícolas como de un salario fijo, garantizado por la estabilidad política del sistema de poder de la Restauración. Serían los mozos pertenecientes a los grupos de poder político y social y a las clases sociales de mayor renta económica.

El análisis de la talla media por grupos socioeconómicos nos aclara bastante en este sentido. Las fuentes consultadas me han permitido recoger la información, aunque dispersa e irregular, del status profesional de más de 4.000 mozos entre 1879 y 1897 . Como se observa en la tabla 4 , son los jornaleros $(1,595 \mathrm{~m})$ y los sirvientes o personal del servicio doméstico $(1,584 \mathrm{~m})$ los que ostentan las estaturas más bajas; mientras que los estudiantes $(1,656 \mathrm{~m})$, comerciantes o empleados de comercio $(1,640 \mathrm{~m})$, trabajadores del sector metalúrgico $(1,635 \mathrm{~m})$, carpinteros $(1,632 \mathrm{~m})$ y trabajadores y artesanos del sector textil $(1,631 \mathrm{~m})$ presentan las estaturas medias más elevadas. Los resultados son a todas luces concluyentes, y es curioso observar cómo son los estudiantes, junto a los comerciantes, los que sobresalen por encima del resto de los sectores socioprofesionales. No me cabe la menor duda de la relación que estos sectores de tallas medias elevadas mantienen con los grupos 


\section{TABLA 4}

Estatura media de los mozos según la distribución de su empleo, 1879-1897

\begin{tabular}{|c|c|c|}
\hline Grupo profesional & $\begin{array}{l}\text { Estatura } \\
\text { media }(\bar{x})\end{array}$ & $\begin{array}{c}\text { Tamaño } \\
\text { muestra }(N)\end{array}$ \\
\hline 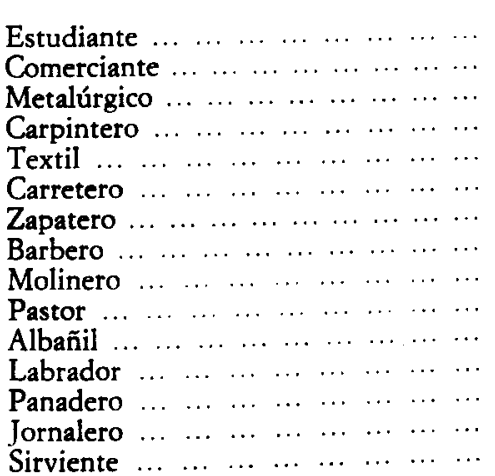 & $\begin{array}{l}1,656 \\
1,640 \\
1,635 \\
1,632 \\
1,631 \\
1,625 \\
1,625 \\
1,623 \\
1,623 \\
1,621 \\
1,621 \\
1,617 \\
1,611 \\
1,595 \\
1,584\end{array}$ & $\begin{array}{r}76 \\
72 \\
85 \\
75 \\
45 \\
20 \\
76 \\
25 \\
20 \\
18 \\
64 \\
213 \\
35 \\
3.148 \\
14\end{array}$ \\
\hline
\end{tabular}

Fuente: Expedientes de Reemplazo. Elaboración propia.

sociales de mayor renta y familias insertas en las estructuras de poder económico y político de ámbito local. El aserto debe relacionarse, además, con lo que señalaba anteriormente: la existencia de un pequeño grupo que supera los $1,70 \mathrm{~m}$, con tendencia al aumento en el área urbana desde 1885 , precisamente cuando la crisis agrícola golpea más duramente a las condiciones de vida y alimentación de los sectores populares, y en concreto de los jornaleros agrícolas. Asimismo, que la crisis agraria afectó también al sector de mozos labradores, arrendatarios y rentistas nos lo puede confirmar, incluso, las tallas medias evaluadas para este grupo vinculado a la renta de la tierra; así, la talla media de éstos se ha estimado en $1,617 \mathrm{~m}$, muy por debajo de sectores socioeconómicos artesanales, aunque por encima de la talla media de jornaleros agrícolas.

Parece oportuno señalar que, en las relaciones que se producen entre estatura y categoría de la fuerza de trabajo, podría darse el caso en que la altura fuese usada como criterio para el ingreso en una determinada ocupación, de manera que los más altos ocuparían aquellos trabajos que requieren una buena presencia física o grado de fuerza física suficiente, tales como empleados de comercio, en el primer caso, o determinados trabajos mecánicos, en el segundo; mientras los bajos de estatura se reservaban a ocupaciones donde tales 
criterios no se utilizaban. Estatura y productividad del trabajo debió ser, por tanto, un factor determinante, aunque reservado en este caso entre trabajos manuales y agrícolas. Sin embargo, este problema constituye un punto débil sobre el que debe profundizarse.

En la mayor parte de los casos, las bajas estaturas iban asociadas a naturalezas físicas endebles y raquíticas. Además de la nutrición y factores sociogenéticos, intervienen, en la configuración de la estatura, el estado de la morbilidad y condiciones de salubridad e higiene tanto pública como privada. Conviene que nos detengamos en ello. Para el medio rural, y en la huerta en concreto, he procedido a evaluar la talla media de los 33 núcleos poblacionales existentes entre 1860 y 1910, agrupándolos en cuatro grandes y diferenciados sectores ${ }^{26}$. Los resultados reflejan fuertes diferencias que deben relacionarse con el tipo de agricultura, grado de diversificación de cultivos agrícolas, penetración del capital comercial y nivel de comercialización agrícola, estructura de la morbilidad y mortalidad, condiciones de salubridad e higiene en las viviendas y lugar de trabajo, además de la nutrición y distribución de la renta. De los resultados obtenidos me interesa resaltar, por el momento, algunas conclusiones que podrán reforzarse en posteriores trabajos más concienzudos y pormenorizados.

El sector I, que agrupa a las poblaciones del piedemonte de la cordillera prelitoral, presenta unas tallas medias en todo momento superiores a las medias de la huerta y de los otros tres sectores, presumiblemente relacionado con la mejora de las condiciones topográficas que posibilitan una mejora de las condiciones ambientales, al estar una gran parte del mismo preservado de las catástrofes hídricas. Sector, también, en el que se procede a una extensa y decidida ampliación de tierras, ya a fines del siglo xix, para el cultivo de los agrios mediante modernas técnicas de regadío.

El sector II ocupa una zona bastante antigua de colonización dentro de la huerta, próxima al casco urbano, y presenta una talla media igual o ligeramente inferior a la talla media de la huerta hasta el período de la crisis agraria, momento a partir del cual ostenta tallas medias más elevadas. Es curioso observar cómo el aumento de la talla en este sector tiene lugar tras la desecación de algunas zonas pantanosas y el consiguiente auge del cultivo del pimiento y su derivación en pimentón, que desde 1895, y sobre todo en la primera década del siglo $\mathrm{xx}$, adquiere grandes dimensiones en sus niveles de producción y comercialización, debido a la presión que ejerce su demanda

${ }^{2}$ Sector I: Alberca, Algezares, Los Garres, Beniaján, Torreagüera, San Benito; sector II: Albatalía, Arboleja, Espinardo, Guadalupe, Javalí Nuevo, Javalí Viejo, La Nora, Churra, Santiago y Zaraiche; sector III: Era Alta, Aljucer, Nonduermas, La Raya, Puebla de Soto, Sangonera, Rincón de Seca y El Palmar; sector IV: Esparragal, Flota, Llano de Brujas, Monteagudo, Puente Tocinos, Raal, Santomera, Santa Cruz, Alquerías y Zeneta. 
de consumo externa. Ello pudo incrementar los ingresos monetarios y la disponibilidad de una mejora en el consumo alimenticio.

El sector III muestra unas tallas medias por encima de la talla media de la huerta hasta 1880 . A partir de entonces y hasta el final del período de observación, en 1910, muestra una regularidad en sus valores negativos respecto de la talla media general. La crisis de la morera, por la enfermedad de la pebrina, y la caída de los precios del capullo de seda en las dos últimas décadas del siglo xIx ${ }^{n}$, al igual que ocurriera con los cereales, debió provocar, al menos acentuar, la ruina de numerosas familias que basaban sus ingresos monetarios en el tradicional cultivo. Este fenómeno, aunque general para toda la huerta, pues su cultivo se extendía por toda ella, adquiere singular importancia en este sector, dada la amplitud de la superficie cultivada y dedicada a las plantaciones de moreral. Por otra parte, este sector se muestra bastante vulnerable a las inundaciones que suceden en los años ochenta del siglo pasado, por la proximidad de los ríos Segura y Requerón.

El sector IV constituye, a tenor de los resultados, el más depresivo, al presentar las tallas medias más bajas de toda la huerta. Además de su escasa diversificación agrícola hasta comienzos del siglo $\mathrm{xx}$, este sector se halla ubicado en el fondo de la depresión que cubre la superficie de la huerta, desde

\section{TABLA 5}

Evolución de la estatura media en distintos sectores de la buerta de Murcia, 1860-1910

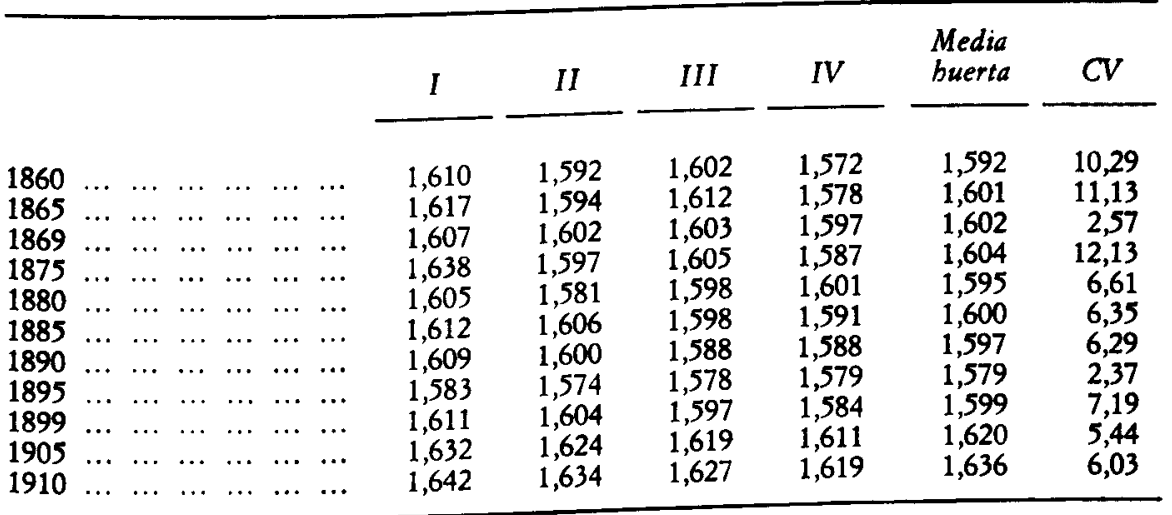

Fuente: Expedientes de Reemplazo. Elaboración propia. La población de los cuatro sectores de la huerta se encuentra agrupada en la nota 26.

${ }^{n}$ Martínez Carrión (1983 b), p. 241. 


\section{TABLA 6}

Diferencias (en centimetros) en la estatura media entre la ciudad, buerta y campo de Murcia, 1860-1930

\begin{tabular}{|c|c|c|c|}
\hline & Ciudad & Ciudad & Huerta \\
\hline & Huerta & Campo & Campo \\
\hline $\begin{array}{llllllll}1860 & \ldots & \ldots & \ldots & \ldots & \ldots & \ldots & \ldots \\
1865 & \ldots & \ldots & \ldots & \ldots & \ldots & \ldots & \ldots \\
1869 & \ldots & \ldots & \ldots & \ldots & \ldots & \ldots & \ldots \\
1875 & \ldots & \ldots & \ldots & \ldots & \ldots & \ldots & \ldots \\
1880 & \ldots & \ldots & \ldots & \ldots & \ldots & \ldots & \ldots \\
1885 & \ldots & \ldots & \ldots & \ldots & \ldots & \ldots & \ldots \\
1890 & \ldots & \ldots & \ldots & \ldots & \ldots & \ldots & \ldots \\
1895 & \ldots & \ldots & \ldots & \ldots & \ldots & \ldots & \ldots \\
1899 & \ldots & \ldots & \ldots & \ldots & \ldots & \ldots & \ldots \\
1905 & \ldots & \ldots & \ldots & \ldots & \ldots & \ldots & \ldots \\
1910 & \ldots & \ldots & \ldots & \ldots & \ldots & \ldots & \ldots \\
1922-25 & \ldots & \ldots & \ldots & \ldots & \ldots & \ldots \\
1926-30 & \ldots & \ldots & \ldots & \ldots & \ldots & \ldots \\
192 & \ldots & \ldots & \ldots\end{array}$ & $\begin{array}{l}3,6 \\
2,6 \\
4 \\
3,8 \\
3,8 \\
2,6 \\
3 \\
3,8 \\
4,6 \\
2 \\
3,1 \\
1,6 \\
-\end{array}$ & $\begin{array}{l}2,7 \\
3,9 \\
3 \\
2,9 \\
3,6 \\
2,2 \\
4,7 \\
4,9 \\
4,8 \\
- \\
- \\
-\end{array}$ & $\begin{array}{r}0,9 \\
-1,3 \\
1 \\
0,9 \\
0,2 \\
0,4 \\
-1,7 \\
-1,1 \\
-0,2 \\
- \\
- \\
-0,7\end{array}$ \\
\hline
\end{tabular}

FUENTE: Expedientes de Reemplazo. Elaboración propia.

las inmediaciones de la ciudad de Murcia al límite con la huerta de Orihuela, y ha estado tradicionalmente cubierto de charcas y áreas pantanosas, lo que le ha hecho especialmente vulnerable a las inundaciones, siendo objeto de continuos focos de paludismo endémico, aun cuando se produce su desecación en el curso del siglo xIx. La serie de inundaciones de los años ochenta debió acentuar el problema de esta enfermedad, que acarreó una extensión de su morbilidad, y pudo intervenir en la complicación de numerosos casos de enfermedades relacionadas con la ausencia total de infraestructura sanitaria en una zona ya de por sí semipantanosa ${ }^{23}$. No es de extrañar, por tanto, que, junto a la tuberculosis y la enteritis, sean la pulmonía y el paludismo las enfermedades y causas de mortalidad que mayor índice de aumento presentan entre 1890-1895, según las estadísticas sanitarias de la época ${ }^{29}$. De las capitales españolas, y por el peso, claro está, de la mortalidad en la población de su huerta, Murcia es el municipio-capital que mayor índice de paludismo ostenta para finales del siglo $x x^{30}$. El impacto que este sector pudo ejercer sobre la morbilidad y mortalidad general del municipio debió ser importante,

Martínez Espinosa (1888), pp. 215 y ss.

- Pérez Picazo (1979), p. 51.

${ }^{30}$ Pittaluga (1903), p. 235. 
aunque en el paludismo, en concreto, más importante que la letalidad de los enfermos es la amplitud de la morbilidad, y todavía más si se considera que esta enfermedad afecta con más intensidad a las edades juveniles y adolescentes $y$, en general, de los adultos. Las secuelas que esta enfermedad dejaba en el organismo de los afectados y las consecuencias negativas que se derivaban de la caída de la productividad del trabajo, al quedar debilitada gran parte de la población activa agraria, son determinantes, y pueden ayudarnos a comprender el estado de estaturas bajas que se han estimado en este sector. Las tallas medias evaluadas constituyen serios indicios de raquitismo y enanismo: las poblaciones de Puente Tocinos, Llano de Brujas, Raal, Santa Cruz, Alquerías, Esparragal, Monteagudo, entre otras, muestran, en más de una ocasión, tallas medias por debajo de $1,550 \mathrm{~m}$.

La relación, pues, entre enfermedad y estaturas bajas se manifiesta aquí en este sector con bastante fidelidad. Y las consecuencias de ello, con los bajos niveles de productividad en el trabajo agrícola, sobre todo en el área de paludismo endémico, van a provocar escasos rendimientos en la producción por unidad de superficie, lo que en nada favorece las condiciones de alimentación y consumo. En más de una ocasión se ha demostrado cómo la amplitud de la morbilidad palúdica ha favorecido el desarrollo de auténticas crisis agrarias, al aumentar los índices de absentismo laboral y debilitar el mercado de trabajo local ${ }^{31}$. Ciertamente, la presencia importante de cuerpos enfermizos y subalimentados, débiles y raquíticos físicamente, no debió favorecer el crecimiento de la producción agrícola, que en este sector se caracteriza, además, por su escasa diversificación y empobrecimiento hasta finales del siglo xIX. La mejora de las condiciones económicas dependía, en este caso, de la mejora de las condiciones de salubridad e higiene del medio. Así que la definitiva desecación a comienzos del siglo xx y la erradicación del paludismo, al menos de sus manifestaciones de naturaleza endémica, mejoró las condiciones ambientales y, con ello, los niveles de vida. De hecho, los sectores II y IV, los más afectados por el paludismo, son los que muestran un mayor crecimiento de las tallas entre 1860 y 1910 . El sector IV aumenta en ese período $4,7 \mathrm{~cm}$, y aún el sector II crece $6 \mathrm{~cm}$ en un período mucho más corto, 1895 1910 , lo que nos muestra la importancia de las modificaciones llevadas a cabo a lo largo de ese período en el medio ambiente y agricultura de la huerta.

Hasta el momento he podido demostrar las diferencias de estatura en distintos sectores de la huerta. Sin embargo, la crisis agrícola, en el período de 1880-1895, redujo las hondas diferencias existentes entre aquéllos, al igual que lo hiciera la crisis de subsistencias de 1868. Los coeficientes de variación anuales muestran un menor grado de dispersión anual de la talla media en

" Pérez Moreda (1984). 
1869 y 1895, que, en el primer caso, se debe a los efectos inmediatos de desnutrición severa y, en el segundo, a la acumulación anual de desnutrición moderada que se prolonga en más de una década. De este modo, la crisis agrícola y el deterioro de las condiciones ambientales, además de reducir las tallas medias en diversos sectores, provocaron una estandarización de las estaturas bajas en el medio rural, lo que, de paso, acentuó las diferencias con la estatura urbana, a pesar de que ésta también muestra una caída durante este período. Así, en la década de los años noventa, la diferencia de tallas entre medio rural y urbano sobrepasa los $3 \mathrm{~cm}$, y en algún momento los $4 \mathrm{~cm}$, en detrimento del medio rural; de tal manera que pudiera existir una correspondencia entre crisis económica y profundización de las diferencias en la estatura entre sectores de desigual renta, y una correlación favorable entre las fases de expansión económica y nivelación de estaturas entre sectores de renta dispar. De la misma manera, se podría establecer una correlación positiva entre alta mortalidad y bajas estaturas ${ }^{32}$, y entre baja morbilidad y mortalidad con altas estaturas, aunque en esta dirección debo proseguir hacia análisis más pormenorizados con inclusión de otras variables demográficas y socioeconómicas.

Sin embargo, parece concluyente que la crisis agraria y el deterioro de las condiciones ambientales provocaron un mayor impacto en las zonas rurales, mientras que en la ciudad, aun sintiéndose afectada, presenta una mayor capacidad de amortiguamiento debido a la naturaleza social y condiciones económicas que la ocupan: propietarios, rentistas, profesiones liberales, funcionarios, comerciantes, artesanos, que en algunos barrios de la ciudad de Murcia superan el 50 por 100 de las categorías ocupacionales (San Lorenzo, San Pedro, San Bartolomé, Santa Catalina, San Nicolás) durante el período de 1879 a $1901^{33}$. También, por este sentido, los niveles de subalimentación y desnutrición eran más elevados en el medio rural, compuesto en su mayor parte por jornaleros agrícolas y pequeños propietarios y arrendatarios, cuestión ésta sobre la que no debo insistir por la profusión de detalles y la abundancia de bibliografía existente al respecto ${ }^{34}$.

El cambio de coyuntura opera en los últimos años del siglo $x I x, y$ este tercer ciclo, que cubre las primeras décadas de nuestra centuria, se caracteriza

32 La caída de las estaturas medias en el período de 1880-1895 se corresponde con el alza de la mortalidad ordinaria (AMM, legs. 291-299); véase, también, Martínez Cartión y Sánchez Iniesta (1984).

3s Pérez Picazo (1979), p. 73

34 Pérez Moreda (1985), p. 9; Martínez Carrión (1983 a), p. 346; Enríquez Morales y. Gelabert González (1978); Fernández García (1977); Simón Segura (1976), pp. 133-149. En Yeste, las propias actas capitulares, en 1882, señalaban cómo de una alimentación basada únicamente en el pan de centeno, maíz, yerbas (sic) y patatas resultaban unas *naturalezas raquíticas y enfermizas" (AMY, $A C$ ses. extra, 2-5-1882). 
por la existencia de dos períodos perfectamente delimitados. El primero muestra un acelerado crecimiento de la estatura tras la salida de la crisis agrícola, y que abarcaría hasta 1912, momento a partir del cual se estabilizan las tallas, no son ciertas fluctuaciones que tienen su relación con la marcha de otros indicadores socioeconómicos que iré señalando. Veámoslo en cifras. A escala municipal, de $1895(\bar{x}=1,588 ; N=1.016)$ a $1910(\bar{x}=1,638 ; N=905)$, el aumento es de $5 \mathrm{~cm}$. Por sectores, el crecimiento se muestra ligeramente superior en la huerta, aunque ya para este período no disponemos de datos para la zona del campo. Mientras en la huerta se consigue una talla de $1,630 \mathrm{~m}$ en 1910 , en la ciudad se alcanza otra de $1,661 \mathrm{~m}$, con $3 \mathrm{~cm}$ de diferencia entre ambas. $Y$, aunque no poseo datos del campo, el decidido aumento que éste muestra entre $1895(\bar{x}=1,568)$ y $1899(x=1,597)$, en tan sólo cuatro años, alcanzando la media de la huerta $(1899, \bar{x}=1,599)$, podría establecerse una similitud para el conjunto de la población rural, que, a mi juicio, tiene bastante que ver con las mejoras ambientales y el proceso de expansión y reconversión agraria que desde los años finales del siglo xIx, y sobre todo en la primera década de nuestro siglo, acontece en la comarca de Murcia.

A lo largo de este período se intensifica la producción de cultivos agrícolas más remuneradores y que más beneficios aportan, tanto en el regadío como en la agricultura de secano extensivo. Objeto de una fuerte presión de la demanda de consumo externa, se favorece, en la huerta, el cultivo del pimiento, ahora en mayor escala e inundando gran parte de la superficie noroccidental, para su elaboración posterior en pimentón; se instalan, asimismo, fábricas conserveras, derivadas de la ampliación de la superficie dedicada a frutales y el aumento de su producción; se revitaliza, incluso, la industria sedera, y se expande el cultivo de los agrios, en particular de la naranja; mientras que retroceden cultivos regresivos económicamente para el regadío, como son los cereales, que veinte años antes inundaban, junto a la morera, el paisaje de la huerta. En el campo se expande el cultivo y la producción de la higuera, el algarrobo, la cebada - cereal más resistente en este área que el trigo-; pero, sobre todo, el cultivo del almendro ${ }^{35}$.

Con la expansión y reconversión de la agricultura, también la ganadería experimenta importantes transformaciones. El ganado mular, entre 1891 y 1914, aun admitiendo la escasa fiabilidad de los recuentos evaluados en las estadísticas ganaderas comarcales, aumenta en casi la mitad el volumen de sus cabezas, lo que está en estrecha relación con el aumento de la producción agrícola, puesto que su crianza y uso iba acompañada a las tareas de labor y acarreo de mercancías en el campo. El número de cabezas de ganado vacuno se multiplica, entre tanto, por cuatro, y el ganado cabrío por siete. El cerdo

${ }^{35}$ Martínez Carrión ( $1983 b$ ), pp. 115-119. A escala general, la expansión agraria, en GEHR (1983). Proceso similar para el caso valenciano, en Garrabou (1985), pp. 80-81. 
ostenta un crecimiento menor, pero importante; pero, a diferencia de otras especies ganaderas, su crianza está fuertemente arraigada entre la población rural, como demuestra la amplitud y el volumen de cabezas porcinas. Este aumento de la producción ganadera no viene sino a confirmar, también, la existencia de una crecida oferta de consumo de carnes y leche que posibilitó el aumento de la demanda de consumo y la diversificación y mejora de la dieta alimenticia de la población y, con ello, de la nutrición.

Esta mejora de las condiciones ambientales y económicas favorece el incremento de los niveles de bienestar de la población. En estos años comienzan a declinar los índices de mortalidad y las enfermedades relacionadas con la miseria y el hambre, tal y como muestra la caída de los índices de enfermedades de naturaleza infecciosa y del aparato digestivo ${ }^{36}$. Las fiebres tifoideas y el paludismo han disminuido su morbilidad y letalidad. La población, mientras tanto, crece, y la emigración disminuye. Todos, o casi todos, los indicadores socioeconómicos permiten confirmar la mejora de las condiciones ambientales y niveles de bienestar de la población. Proceso que corre paralelamente al sensible aumento de la estatura media de los mozos. La correspondencia existente entre expansión económica y elevación de la talla vuelve a presentarse con bastante fidelidad.

La dieta alimenticia debió mejorar no sólo en la cantidad de los productos consumidos. La diversificación de productos hortifrutícolas y la intensificación de los ya tradicionales debió suponer una mejora cualitativa en relación con la composición de la dieta en las últimas décadas del siglo xIx y, en general, a épocas anteriores. Se ha visto un incremento de la producción de patatas en modo considerable, lo que, unido al incremento de la producción de cereales, debió aumentar el volumen de la capacidad de consumo familiar, desapareciendo las carestías. Por otro lado, se detecta un incremento de legumbres, verduras y frutas, que debieron enriquecer, a la postre, la composición vitamínica de los nutrientes consumidos ${ }^{37}$. Está demostrado que el grupo de vitaminas $D$ desempeña un papel esencial en el mecanismo de absorción del calcio por los huesos, por lo que su deficiencia provoca raquitismo y malformaciones en el desarrollo del organismo. De otra parte, al incrementar el consumo de carnes, leche y huevos, componentes básicos por su potencial proteínico, se incrementó el desarrollo muscular del organismo. La ingestión, pues, de mayor cantidad de proteínas animales, vitaminas y sales minerales a lo largo de las primeras décadas del siglo xx pudo favorecer el crecimiento de la estatura.

La distribución de frecuencias agrupadas según la altura de los mozos permite entresacar algunas conclusiones más en este sentido. De un lado, se

* Martínez Carrión y Sánchez Iniesta (1984), p. 410.

${ }^{37}$ Salazar (1911), pp. 103-106. 
reduce la proporción de los mozos que no superan $1,50 \mathrm{~m}$. En conjunto, se pasa de un 10,7 por 100 en $1895-99$ a un 2,9 por 100 en $1907-11$. El raquitismo y el enanismo casi se ha erradicado en el curso de las primeras décadas de nuestro siglo. Por otro, la proporción de mozos que superan $1,70 \mathrm{~m}$ aumenta, pasando de un 7,8 por 100 en $1895-99$ a una proporción de 14,4 por 100 en el quinquenio de 1907-11. En este proceso de cambio en la talla de los mozos se ha beneficiado el sector rural, dado su índice de crecimiento, duplicándose el número de mozos que podríamos considerar como «desarrollados». En la ciudad, la tasa de crecimiento no es tan elevada, aunque sigue mostrando una relación mayor al sector rural por el peso de su estructura social. Si comparamos, además, la evolución de los grupos de estatura II y III de la tabla 2, se comprueba cómo la mayor parte de los mozos estaban comprendidos en el grupo II (46,1 por 100) hacia mediados del siglo xIx, mientras que en 1910 la proporción era de 27,2 por 100 , momento en que predomina el grupo III (56,7 por 100), superior a la cifra que mostraba en 1860 $(41,4$ por 100$)$. El cambio de un grupo a otro de mayor talla confirma el crecimiento de las estaturas hacia comienzos del siglo xx y la mejora de los niveles de bienestar. La caída de enfermedades ligadas a raquitismo, debilidad congénita y encanijamiento de la población infantil y juvenil favoreció el crecimiento de la talla de los adolescentes a la edad de 19 años. Incluso en la huerta, los niveles diferenciales de talla, mostrados en varios sectores hacia mediados del siglo $\mathrm{xIx}$, disminuyen a comienzos del siglo $\mathrm{xx}$, tal y como muestra la escasa dispersión de los coeficientes de variación para 1901-1910, a pesar de que se mantiene la tendencia de las tallas más elevadas en los sectores I y II, precisamente aquellos que muestran el impacto de una agricultura comercial más dinámica y diversificada.

Sin embargo, el período de crecimiento económico que opera en tierras murcianas desde los últimos años del siglo xIX, apoyado en la expansión de una agricultura comercial por estímulos de la demanda externa, entra en crisis a causa del conflicto bélico europeo. Se reducen las exportaciones al extranjero y la demanda interna de consumo no suple el exceso de la oferta de productos agrícolas. La crisis económica se agudiza hacia 1917.18, ocasionando con ello una crisis social en el sector rural que se manifiesta en el deterioro de las condiciones de vida y el incremento de la emigración ${ }^{38}$. La prensa de la época se hace eco del malestar de los jornaleros ante el alza del coste de los artículos de consumo de primera necesidad, y en aquélla se aprecia una clara diversificación de productos básicos de consumo respecto a épocas anteriores; sin embargo, no refleja el consumo de carne fresca ${ }^{39}$. Aparece reflejado, en cambio, el consumo de bacalao y sardinas, estas últimas para almorzar

3. Nadal (1984), pp. 195 y ss.

3. AMM (El Liberal, 18-4-1918). 
y el primero para la cena. Si ya en la segunda mitad del siglo XIX se apreciaba cierto consumo de salazones, ahora, en las primeras décadas del siglo $\mathbf{x x}, \mathbf{y}$ con ocasión de la crisis económica, se generaliza su consumo, más acentuado entre el proletariado urbano y jornaleros agrícolas, debido sobre todo a la diferencia de precio respecto de las carnes frescas, que entrarían, sin embargo, en la dieta alimenticia de familias con mayor renta. Cabe señalar que las deficiencias en proteínas animales se suplían considerablemente con el masivo consumo de abadejo, rico en albúmina animal ${ }^{*}$.

Por los datos que presenta la ciudad y una muestra representativa de la huerta, creo poder mostrar el impacto que la crisis social y económica, producida a causa de la guerra europea, ejerció sobre la pérdida cualitativa de la composición de los nutrientes. La caída de las rentas debió propiciar un deterioro de las condiciones de vida $y$, aunque sabemos bien poco de la morbilidad de este periodo, sí se ha evaluado una ligera caída de la talla media de los mozos entre 1917 y 1922, aproximadamente, en $1 \mathrm{~cm}$. La sustitución de carne fresca por el consumo de salazones, bacalao y sardinas en particular, así como una mayor diversificación en verduras y hortalizas y frutas, presumiblemente permitió amortiguar y aminorar los efectos que en otro tiempo una crisis económica similar pudo haber producido en el consumo de los jornaleros. Si en el siglo XIX una crisis de subsistencias provocaba situaciones colectivas de hambre cuantitativa, favoreciendo el desarrollo del raquitismo y la muerte por inanición en casos extremos, ahora, en las primeras décadas del siglo $\mathrm{xx}$, la crisis económica podía favorecer situaciones de hambre en forma cualitativa, restringiendo el consumo de ciertos productos básicos, como la carne, leche y huevos, hasta incluso otros nutrientes, pero en ningún-modo mostrar los efectos tan exacerbados de otras épocas anteriores; así al menos lo confirman las tasas de mortalidad. Aunque es muy sintomático, sin embargo, que la gripe de 1918 , que tanta intensidad mortífera produjo en el medio rural, tan escaso de infraestructura sanitaria, aconteciera en plena crisis social y económica. Con todo, el grado de diversificación de consumo alimenticio había mejorado respecto del siglo pasado, de tal manera que ante una situación de crisis y alza del coste de la vida bien pudo producirse un proceso de sustitución de productos de consumo más caros por otros más baratos en el mercado: el ejemplo de los salazones respecto de carnes frescas, y el fuerte consumo de hortalizas (patatas en primer lugar), legumbres (arroz, habichuelas, garbanzos) y verduras en general, puede ser ilustrativo. Es curioso observar, además, como en los años-consecutivos a la crisis, la proporción de mozos altos disminuye y aumenta, en el lado opuesto, la proporción de los considerados como bajos o raquíticos, aunque en bajas proporciones. Con ello no

* Flores de Lemus (1976), pp. 429-433, citado en GEHR (1979), p. 118. 
quiero restarle importancia a los efectos que la crisis de 1917-19 produjo en la caída del poder adquisitivo y en la renta de sectores populares. Otros indicadores socioeconómicos parecen demostrar el deterioro importante de los niveles de bienestar: además del impacto de la morbilidad gripal y la importancia de su letalidad, la emigración rural se dispara hasta los primeros años de la década de los veinte, actuando de válvula de escape ante la presión ejercida por el incremento del coste de la vida y la caída en los niveles de empleo. La disminución de la población, más radical en los núcleos de campo que en los de la huerta, es un hecho verificable a través de los padrones de población municipal.

\section{TABLA 7}

Evolución de la estatura en la ciudad y buerta entre 1912-1922

\begin{tabular}{|c|c|c|c|c|}
\hline & \multicolumn{2}{|c|}{ Ciudad } & \multicolumn{2}{|c|}{ Huerta } \\
\hline & $\bar{x}$ & $N$ & $\bar{x}$ & $N$ \\
\hline $\begin{array}{llllllll}1912 & \ldots & \ldots & \ldots & \ldots & \ldots & \ldots & \ldots \\
1917 & \ldots & \ldots & \ldots & \ldots & \ldots & \ldots & \ldots \\
1919 & \ldots & \ldots & \ldots & \ldots & \ldots & \ldots & \ldots \\
1920 & \ldots & \ldots & \ldots & \ldots & \ldots & \ldots & \ldots \\
1921 & \ldots & \ldots & \ldots & \ldots & \ldots & \ldots & \ldots \\
1922 & \ldots & \ldots & \ldots & \ldots & \ldots & \ldots & \ldots\end{array}$ & $\begin{array}{l}1,656 \\
1,649 \\
1,643 \\
1,641 \\
-\end{array}$ & $\begin{array}{l}157 \\
192 \\
204 \\
228 \\
-\end{array}$ & $\begin{array}{l}1,637 \\
1,636 \\
- \\
\overline{1} \overline{1,628}\end{array}$ & $\begin{array}{l}269 \\
224 \\
- \\
\overline{171}\end{array}$ \\
\hline
\end{tabular}

FUENTE: Expedientes de Reemplazo. Elaboración propia.

Superados los efectos de la crisis, y retomados los hilos de la expansión agrícola en la década de los años veinte, existen indicios de una ligera mejora de los niveles de vida, que reflejan la caída de los índices de mortalidad y el crecimiento de la población rural y urbana. También los indicadores antropométricos para el segundo quinquenio de la década muestran cierta mejora de sus niveles en relación a la primera década del siglo $\mathrm{xx}$, aunque debe tenerse en cuenta el cambio de la edad de incorporación a filas en 1912, que se incrementa a 21 años, y, de otro lado, la desaparición del sistema de mozos redimidos. Factores que no parecen alterar la evolución de la tendencia de la estatura mostrada hacia ese periodo. La talla media a finales de los años veinte, entre 1926 y 1930 , se estima en $1,641 \mathrm{~m}(N=1.738)$; por sectores, en la huerta se estima en $1,639 \mathrm{~m}(N=760)$, y en el campo, para la población de Corvera $(N=122)$, en $1,632 \mathrm{~m}$. Dada la escasa representatividad de la 
muestra disponible para la ciudad, al disponer tan sólo de datos del barrio de San Andrés, uno de los distritos marginales de la ciudad, he creído oportuno no presentarlos. Aun así, creo poder afirmar que para finales del período observado se ha conseguido limar las diferencias que antaño mostraba el sector rural del urbano. El acercamiento de las estaturas en uno y otro sector, en un período donde la muestra es bastante representativa y significativa, entre 1922 y 1925 , es bien palpable, puesto que la diferencia mostrada era tan sólo de $1,6 \mathrm{~cm}$. Por otro lado, habría que destacar la escasa proporción conseguida entre mozos considerados como mal. nutridos o poco desarrollados físicamente hacia los años veinte: entre 1926 y 1930, la relación era de 0,98 por 100 para todo el municipio, mientras que los altos mostraban una relación del 14,67 por 100, lo que muestra el escaso nivel de raquitismo y enanismo de la población masculina alcanzado a estas alturas del siglo $\mathrm{xx}^{41}$.

\section{A modo de conclusión}

Cabría mostrar el logro que entre 1860 y 1930 se produce en el tamaño de la talla en torno a la edad de 19-21 años: el crecimiento para el conjunto de la población masculina se ha estimado en $4,2 \mathrm{~cm}$. Crecimiento que opera con más intensidad en el curso de la primera década del siglo $\mathbf{x x}$, y debe vincularse al modo en que se desenvolvieron las transformaciones económicas y demográficas; en definitiva, las condiciones ambientales ${ }^{2}$. Las grandes diferencias de estatura que venía ostentando el sector rural respecto del urbano a lo largo de la segunda mitad del siglo xIX se disipan notablemente hacia la tercera década del siglo xx. La evolución de la estatura de los mozos llamados a reclutamiento parece que ha reportado más beneficios a los mozos del sector rural, lo que, por otra parte, viene a demostrar la importancia de las modi-

"En Yeste, para el periodo 1926-1935, he estimado también una relación pequeña (1,75 por 100), mientras que en 1899-1902 era bastante más elevada (15,22 por 100). Véase Martínez Carrión (1983 a), p. 346.

2 Continuando las comparaciones con la comarca de Yeste, donde la agricultura se manifiesta más atrasada y en difíciles condiciones de desarrollo por su orografía montañosa, la evolución de la estatura muestra un cambio ciertamente significativo. Así, desde 1899 (1899-1902) a 1930 (1925-1935) experimenta un aumento de 2,7 cm, que en Murcia, en ese mismo período, presenta en $3,3 \mathrm{~cm}$ :

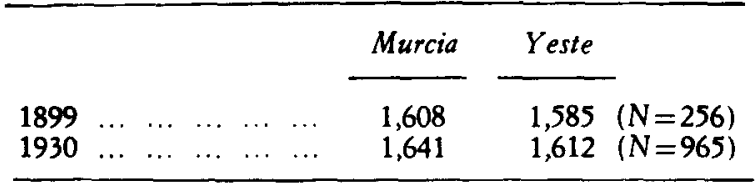

FurNTE: Expedientes de Reemplazo. Elaboración propia. 
ficaciones acontecidas en el medio ambiente. Ciertamente, es arriesgado relacionar los cambios específicos de la estatura por clases sociales y regiones con la naturaleza y amplitud del desarrollo económico. Sin embargo, disponemos de la información suficiente que corrobora la hipótesis de la relación que existe entre la nutrición y la salud con el estado físico y la estatura de las poblaciones. Los cambios mostrados en la agricultura, en el caso que nos ocu$\mathrm{pa}$, con la intensificación de la producción agrícola y ganadera, y el aumento y expansión de su comercialización, así como de los sectores productivos dependientes de aquélla, pudo favorecer una mejora de las condiciones socioeconómicas de las clases trabajadoras, entre productores y consumidores. Asimismo, una cierta diversificación de los componentes nutritivos de la dieta alimenticia en los sectores populares. Factores que están estrechamente ligados a la mejora de las condiciones de salubridad e higiene en la población, tal y como corroboran la caída de la morbilidad y el declive de las defunciones infantiles y juveniles en las primeras décadas del siglo $\mathrm{xx}$. La reciprocidad de las relaciones que se establecen entre nutrición y sanidad serán determinantes en la evolución de la estatura, aún teniendo en cuenta la importancia de factores étnicos y sociogenéticos.

Finalmente, y contra la impresión popular, bastante generalizada, de cierta teoría que señala un crecimiento ininterrumpido y progresivo de la estatura media en el colectivo humano a lo largo del tiempo, he de apostillar en su contra la existencia de ciclos en la tendencia de la estatura que se relacionan con la dimensión y naturaleza de los cambios económicos, sociales y demográficos y, en general, con un mayor grado de bienestar entre el capital humano.

\section{BIBLIOGRAFIA}

ANES, Gonzalo (1970): Las crisis agrarias en la España Moderna, Madrid: Taurus.

Aron, J.-P.; Dumont, P., y Le Roy Ladurie, E. (1972): Anthropologie du Conscrit Français d'après les comptes numériques et sommaires du recrutament de l'armée (1819-1826), París-La Haya: Mouton.

As r ton, T. S. (1949): «The Standard of Life of the Workers in England 1790-1850", suplemento IX, pp. 19-38; existe trad. castellana en HAYEK, F. A. (ed.) (1973): El Capitalismo y los bistoriadores, Madrid: Unión Editorial, pp. 123-156.

Enríquez Morales, M. J., y Gelabert González, J. E. (1978): “Un aspecto del consumo alimenticio en la España de la segunda mitad del siglo XIX», Hispania, 140, pp. 617-635.

Fernández García, A. (1979): «Parámetros del nivel de vida del campesinado, 1880 1890», en ANES, G., y otros: La economía agraria en la Historia de España, Madrid: Alfaguara, pp. $335-344$.

Flores DE LEMUS, A. (1976): «Algunos datos estadísticos sobre el estado actual de la economía española (versión de A. García de Blas), Hacienda Pública Española, pp. $421-465$. 
Floud, R., y WACH TER, K. (1982): «Poverty and Physical Stature: Evidence on the Standard of Living of London Boys, 1770-1870m, Social Science History, 6, 4, pp. 422-452.

Floud, R. (1983): «The Heights of European since 1750: A New Source for European Economic History" (NBER, 1318), texto mecanografiado.

- (1984): Measuring the Transformation of the European Economies: Income, Health and Welfare, Londres: Center for Economic Policy Research (Discussion Paper Series, núm. 33).

- (1985): «The Physical State of the British Working Class, 1860-1914: Evidence from Army Recruitsm, ponencia leída en el coloquio sobre Problems and Methods in the History of Medicine, Corpus Christi College, Cambridge, 25-28 marzo.

Fogrl, R. W.; Engerman, S. L., y Trusell, J. (1982): «Exploting the Uses of Data on Heigth: The Analysis of Long-Term Trends in Nutrition, Labor Welfare and Labor Productivity», Social Science History, 6, 4, pp. 401-421.

Fogel, R. W.; Engerman, S. L.; Floud, R.; Steckel, R. H.; Trusell, T. J.; Wach Ter, K. W.; Sokoloff, K.; Villaflor, G.; Margo, R. A., y Friedman, G. (1983): «Secular Changes in American and British Stature and Nutrition», Journal of Interdisciplinary History, XIV, 2, pp. 445-481.

Garrabou, R. (1975): «La crisis agraria espanyola de finals del segle: una etapa del desenvolupament del capitalisme», Recerques, 5, pp. 163-216.

- (1985): Un fals dilema. Modernitat o endarreriment de l'agricultura valenciana (18501900, Valencia: Institució Alfons el Magnànim.

Garrabou, R., y Sanz, J. (1985): Historia agraria de la España Contemporánea. 2. Expansión y crisis (1850-1900), Barcelona: Crítica.

Gómez Mendoza, A., y Pérez Moreda, V. (1985): «Estatura y nivel de vida en la España del primer tercio del siglo XX», Moneda y Crédito, 174, pp. 29-64.

Grenne, L., y Jo hnson, F. E. (1980): Social and Biological Predictions of Nutritional Status, Physical Growth, and Neurological Development, Nueva York.

Grupo DE Estudios dE Historia RuRal (1979): «Contribución al análisis histórico de la ganadería española, 1865-1929" (2." parte), Agricultura y Sociedad, 10, pp. 105.170.

- (1983): «Notas sobre la producción agraria española, 1891-1931», Revista de Historia Económica, I, 2, pp. 185.252.

HoBsBawn, E. J. (1963): «The Standard of Living during the Industrial Revolution: A Discussion», Economic History Review, XVI, 1, pp. 119-134.

- (1977): Industria e Imperio. Una bistoria económica de Gran Bretaña desde 1750, Barcelona: Ariel (trad. castellana de la versión inglesa de 1968).

- (1979): Trabajadores. Estudios de bistoria de la clase obrera, Barcelona: Crítica (trad. castellana de la versión inglesa de 1964).

Komlos, John (1985a): "Stature and Nutrition in the Habsburg Monarchy: The Standard of Living and Economic Development in the Eighteenth Century», The American Historical Review, 90: 5, pp. 1149-1161.

- (1985 b): «Patterns of Children's Growth in East-Central Europe in the Eighteenth Century», Annals of Human Biology (en prensa).

- $(1985 \mathrm{c})$ : «Height Increments in Eighteenth Century Hungary», mecanografiado.

Lindert, P. H., y Williamson, J. G. (1983): «English Worker's Living Standard during the Industrial Revolution: A New Look», Economic History Review, XXXVI, 1, pp. 1-25.

Margo, R. A., y Steckel, R. H. (1983): «Height of Native-Born Whites During the Antebellum Period», Journal of Economic History, XLIII, 1, pp. 167-174.

Martf́nez Carrión, J. M. (1981): «Posibilidades y limitaciones de análisis en las fuentes de tipo demográfico para la primera fase de la era estadística, 1870-1935», II Jornadas de Metodología y Didáctica de la Historia, Universidad de Cáceres (comunicación inédita).

- (1983 a): La población de Yeste en los inicios de la transición demogrifica, 1850-1935, Albacete: CSIC-IEA. 
- (1983 b): Los inicios de la modernización de la agricultura en el municipio de Murcia, 1900-1935, Comunidad Autónoma de Murcia (memoria inédita).

Martínez Carrión, J. M., y Sánc hez Iniesta, T. (1984): «El declive de la mortalidad en el área rural albacetense. Siglos XIX-XX», Congreso de Historia de Albacete. Vol. IV. Edad Contemporánea, Albacete: CSIC-IEA, pp. 395-420.

Martinez Espinosa, M. (1888): Apuntes de climatologia, saneamiento e bigiene en Murcia y su buerta, Murcia: Imprenta El Diario.

Moral Ruiz, J. del (1979): La agricultura española a mediados del siglo XIX (1850-70). Resultados de una encuesta agraria de la época, Madrid: Servicio de Publicaciones Agrarias.

NAdAl, J. (1984): La población española. Siglos XVI al XX, Barcelona: Ariel, 4.* ed.

PÉrez Moreda, V. (1980): Las crisis de mortalidad en la España interior. Siglos XVI-XIX, Madrid: Siglo XXI.

- (1984): «Crisis demográficas y crisis agrarias: paludismo y agricultura a fines del siglo xvinm, Congreso de Historia Rural. Siglos XV al XIX, Universidad Complutense de Madrid, pp. 333-354.

- (1985): "Consum deficitari, fam i crisis demogràfiques a l'Espanya dels segles XVI-XIX», Estudis d'Historia Agraria, 5, pp. 7-24.

Pérez Picazo, M. ${ }^{\star}$ T. (1979): Oligarquía urbana y campesinado en Murcia, 1875-1902, Murcia: Academia Alfonso $\mathrm{X}$ el Sabio.

Pérez Picazo, M." T., y Lemeunier, G. (1984): El proceso de modernización de la Región Murciana (siglos XVI-XIX), Murcia: Editora Regional.

Pittaluga, G. (1903): Investigaciones y estudios sobre el paludismo en España (19011903), Barcelona.

Salazar, Z. (1911): La agricultura en la Provincia de Murcia, Madrid: Tip. Jaime Ratés.

SCH Olliers, P., y VANDERBR OEKE, C. (1982): "The Transition from Traditional to Modern Pattern of Demand in Belgium», en BaudeT, H., y Meulen, H. van der (eds.): Consumer Behaviour and Economic Growth in the Modern Economy, Londres: Croom Helm, pp. 23.71.

Simón SegurA, F. (1976): "Aspectos del nivel de vida del campesinado español en la segunda mitad del siglo XIX. La alimentación», Económicas y Empresariales, 3, pp. $133-149$.

Sokoloff, K. L., y Villaflor, G. D. (1982): "The Early Achievement of Modern Stature in America», Social Science History, 6, 4, pp. 453-481.

STECKEL, H. R. (1979): «Slave Height from Coastwise Manifest», Explorations in Economic History, XVI, 4, pp. 363-380.

- (1983): «Height and Per Capita Income», Historical Methods, XVI, 1, pp. 1-7.

Tanner, J. M. (1981): A History of the Study of Human Growth, Cambridge: Cambridge University Press.

- (1982): «The Potential of Auxological Data for Monitoring Economic and Social WellBeing", Social Science History, 6, 4, pp. 571-581.

TAYLOR, A. J. (ed.) (1975): The Standard of Living in Britain in the Industrial Revolution, Londres: Methuen (versión castellana de Fernando Reigosa, Madrid, Ministerio de Trabajo y Seguridad Social, 1985).

VANDERBROEKE, C. (1981): «De Keurlingenlijsten als sociaal-demografische meter», De Leiegouw, XXIII, 2, pp. 235-273.

Vilar Ramírez, J. B. (1975): Emigración española a Argelia (1830-1900). Colonización bispánica de la Argelia trancesa, Madrid: CSIC.

WACH TER, K. W. (1981): «Graphical Estimation of Military Height», Historical Methods, $\mathrm{XIV}, 1$, pp. $31-42$. 